\title{
IX.
}

Aus dem pathologischen Laboratorium in Amsterdam.

\section{Die Ursache der giftigen Wirkung der chlorsauren Salze.}

$$
\text { Von }
$$

B. J. Stokvis

in Amsterdam.

Im letzten Decennium hat die Literatur eine ziemlich reiche Casuistik von Intoxicationen durch Kali chloricum beim Menschen aufzuweisen. ${ }^{1)}$ Viele dieser Fälle wurden bei Kranken (Diphtheritis $\mathfrak{u}$. s. w.) beobachtet, so dass ein Theil der Vergiftungserscheinungen und öfters anch der letale Ausgang nicht mit absoluter Sicherheit ausschliesslich der Intoxication zugeschrieben werden konnte; in den meisten derselben dagegen war die Intoxication eine ganz zufällige, durch Versehen oder Unachtsamkeit beim gesunden Menschen hervorgerufene, so dass die giftige Wirkung des gebrauchten Chlorats iiber allen Zweifel erhoben war.

Nun ist die Frage, auf welche Weise das Kali chloricum seine giftige und therapeutische Wirkung entfaltet, eine besonders wichtige. Die Meinung, welche sich darüber in den letzten Jahren, kraft der interessanten Untersuchungen Binz's ${ }^{2}$ ) und Marchand's ${ }^{3}$ ), allgemeine Geltung zu verschaffen gewusst hat, scheint eine so plausible, dass sie wohl als die jetzt fast alleinherrschende betrachtet werden kann. Es ist die sehon von Foureroy und Aly on befurwortete, wobei angenommen wird, dass das Chlorat im lebenden Organismus einen Theil seines Sauerstoffes abgibt, und, wie Fourcroy sich ausdrückt „sert à oxygèner l'èconomie".

1) Merkwürdigerweise ist in Holland, wo tagtäglich Kaliumchlorat vorgeschrieben und gebraucht wird, bis jetzt, soviel mir bekannt, noch nie ein Fall von tödtlicher Vergiftung durch diese Substanz vorgekommen oder wenigstens beschrieben worden.

2) Dieses Archiv. X. Bd. S. 153. 1879.

3) Virchow's Archiv. LXXII. Bd. 1879. 
Das chlorsaure Salz wird von dem lebenden Protoplasma zum Theil za Chlorid reducirt, der dabei frei werdende Sauerstoff bildet, sobald das Chlorat sich im Blut befindet, mit dem Hämoglobin desselben die feste Sauerstoffverbindung, welche nach dem Vorgange Hoppe-Seyler's Methämoglobin genannt wird; es findet also unter dem Einflusse grosser Dosen eine Zersetzung des Blutes statt, welche entweder direct oder durch Anbäufung von Zerfallsproducten den Tod herbeifuhren kann - so lautet in wenigen Worten die jetzt allgemein angenommene Lehre. Es sei mir der Versuch erlaubt, die Unrichtigkeit dieser Lehre in den folgenden Seiten darzuthun, im Anschluss an einige experimentelle Arbeiten, welche in meinem Laboratorium ausgeführt worden sind und welche sowohl die Reduction der Chlorate im lebendigen thierischen Organismus als die giftige Wirkung dieser Salze selbst betreffen. An erster Stelle werde ich die Frage nach der Reduction der Chlorate im lebendigen thierischen Organismus, wie sie von Dr. K i m m y ser in seiner InauguralDissertation ${ }^{1}$ ) behandelt worden ist, besprechen, und darauf die Mittheilung der weiteren von dem Arzt H. C. M. van Gorkom und mir selbst über die Ursache der giftigen Wirkung der Chlorate angestellten Versuche folgen lassen.

I. Die Reduction der chlorsauren Salze im lebenden Organismus und die Ausscheidung mit dem Harn des in den thierischen Kärper eingeführten Chlorats.

Wenn die Wirkung der Chlorate auf einer Reduction derselben im thierischen Körper beruht, so wird diese Reduction sich wohl am ersten dadurch erkennen lassen, dass die in den lebenden Körper eingefuihrte Chloratmenge nicht ganz als solche, sondern zum Theil als Chlorid mit dem Harn wieder ausgeschieden wird. Als Dr. Kimmyser seine Untersuchungen über diesen Gegenstand anfing, lagen relativ nur wenig Untersuchungen darüber vor und die Resultate dieser Untersuchungen standen mit einander im deutlichsten Widerspruch. Wöhler, Is ambert, Hirne und Rabuteau hatten einerseits gezeigt, dass innerlich genommenes Kaliumchlorat bei Menschen und Hunden ganz unverändert wieder mit dem Harn ausgeschieden wird, hatten aber auf eine mögliche Zunahme des Chlors im Harn unter diesen Umständen keine Rücksicht genommen. Andererseits

1) W. C. Kimmyser, Onderzoekingen over de reductie van chloraten in het levend organismus. Academisch Proefschrift. Amsterdam 1884. 
behauptete $\mathrm{G}$ iu bler, eine deutliche Vermehrung der Harnchlormenge nach der Verabreichung von Kaliumchlorat beim Menschen gefunden zu haben, und obgleich seine Untersuchungsmethode ebensowenig wie die von ihm erhaltenen Resultate als zuverlässige betrachtet werden können, so stimmte doch seine Schlussfolgerung mit den inzwischen von Binz und Marchand veröffentlichen Thatsachen und besonders mit dem im Jahre 1883 von Gaethgens ${ }^{1}$ ) bei einem Hunde erhaltenen Resultate, dass von $10 \mathrm{~g}$ eingeführtem Kaliumchlorat ca. $2 \mathrm{~g}$ im Körper reducirt werden und nicht als solches, sondern als Chlorid im Urin erscheinen. Es lag eben in diesem grellen Widerspruch eine Aufforderung zu einer neuen Versuchsreihe vor, und als eine solche von Dr. Kimmyser fast beendet war und seine Dissertation zum Abdruck gelangte, da erschien die fleissige und verdienstvolle Monographie v. Mering's ${ }^{2}$ ), welche im Ganzen eine höchst willkommene Bestätigung der von Ersterem erhaltenen Resultate brachte.

Dr. Kimmyser experimentirte am Mensehen, Hunde und Kaninchen. Zur Bestimmung des Chlors und des Chlorats im Harn bediente er sich der von Salkowski modificirten Vollhard'schen Methode, und zwar so, dass von jedem Harn zwei Chlorbestimmungen gemacht wnrden, eine in dem Harn als solchem und eine zweite in der Harnasche. Zur Erlangung der Harnasche wurden $10 \mathrm{ccm}$ Harn mit $2 \mathrm{ccm}$ Natriumcarbonat in einer Platinschale eingedampft, getrocknet, während einer Stunde einer Temperatur von $120^{\circ} \mathrm{C}$. ausgesetzt, dann einfach verbrannt und darauf mit etwas aufgepulvertem Kalisalpeter so lange geglüht, bis eine vollkommen weisse Asche erhalten war. Diese Asche wurde in einigen Tropfen reiner Salpetersäure gelöst, zur Entfernung der salpetrigen Säure einen Augenblick erhitzt und die erhaltene Harnaschelösung wieder nach Vollhard-Salkowski zur Bestimmnng des Chlor verwendet. Aus der Differenz zwischen den bei der Chlorbestimmung in dem Harn als solehem und den bei derjenigen in der Harnasche erhaltenen Zahlen liess sich die vorhanden gewesene Chloratmenge leicht berechnen. 4 Vorversuche ergaben, dass in auf diese Weise untersuchtem Menschen- und Kaninchenharn von $200 \mathrm{mg}$ zugesetztem Natriumchlorat im Mittel $192 \mathrm{mg} \mathrm{zu-}$ rückgefunden wurden. Die Bestimmung des Chlorats war also bis auf $\pm 4-8$ Proc. der vorhandenen Menge genau. Andererseits ergab sich bei Abwesenheit von Chlorat im Harn eine absolute Uebereinstimmung zwischen der Chlorbestimmung im Harn als solchem und derjenigen in der Harnasche. Während sich nun für Menschen- und Kaninchenharn diese Methode als vollkommen zuverlässig ergab - wenn auch nicht so genau wie die später von v. Mering angegebene, bei welcher das Chlorat nicht durch Erhitzen, sondern durch Behandlung mit Zinkstaub und verdünnter Schwefelsäure zu Chlorid reducirt wird - so lieferte dennoch

1) Berliner klinische Wochenschrift. 1883. 18. Juni.

2) Das chlorsaure Kali. Berlin 1885. 
ihre Verwendung beim Hundeharn von Zeit zu Zeit erhebliche Schwierigkeiten, welche nicht so sehr den im Hundeharn enthaltenen schwefelhaltigen Substanzen zugeschrieben werden konnten, als vielmehr auf noch nicht genïgend aufgeklärten Verhältnissen beruhen müssen. ${ }^{1}$ ) In der grössten Mehrzahl der Bestimmungen führte aber die angegebene Methode auch beim Hundeharn zum Ziele.

Als Chlorat kam ausschliesslich, um jede Kaliwirkung auszuschliessen, vollkommen reines Natriumchlorat in Anwendung. Besondere Sorgfalt ward auf die chemische Reinheit des gebrauchten Salzes verwendet, da sich ergeben hatte, dass einzelne Handelspräparate, obgleich als Natrium chloricum purissimum bezeichnet, nicht die für reines Natriumchlorat festgestellten Löslichkeitsverhältnisse und dazu neben einer sauren Reaction einen deutlichen Geruch nach freiem Chlor zeigten. Alle die zur quantitativen Analyse nothwendigen Flüssigkeiten wurden ausserdem vor dem Gebranch jedesmal selbstverständlich auf möglichen $\mathrm{Cl}$-Gehalt geprüft.

Die erste Versuchsreihe, welche ich hier mittheilen will, hat Dr. Kimmyser an sich selbst angestellt. Er hatte seine Diät so geregelt, dass er auf Stickstoffgleichgewicht war und die mit den Speisen eingeführte Kochsalzmenge jeden Tag vollkommen dieselbe $= \pm 12,8 \mathrm{~g}$ in 24 Stunden war. Am 4. Tage nahm er des Morgens beim Frühstiuck $4 \mathrm{~g} \mathrm{NaClO}$, welche er in Substanz der von ihm gebrauchten Milch zusetzte. Die Resultate dieser Versuchsreihe mit Bezug auf $\mathrm{NaCl}$ - und $\mathrm{NaClO}_{3}$-Menge sowie anf die Harnstoffmenge des in 24 Stunden gelassenen Harns sind in folgender Tabelle (S. 173) ubersichtlich dargestellt.

In dieser Versuchsreihe wird ein Theil des eingenommenen Chlorats nicht im Harn zurïekgefunden und zeigt sich am Tage des Chloratgebrauches eine nicht unbedeutende Zunahme des Chlors. Es scheint dieser Befund für eine Reduction des Chlorats zu sprechen.

1) v. Mering machte die im Hundeharn anwesenden schwefelhaltigen Körper für die zu hohen Zahlen verantwortlich, welche man bisweilen bei der directen Chlorbestimmung in diesem Harn erhält. Der von Dr. Kimmyser verwendete Hundeharn lieferte aber, bei Abwesenheit des Chlorats, sowohl bei der directen Bestimmung als bei der Bestimmung in der Harnasche immer gut übereinstimmende Werthe. Dagegen wird einzelne Male bei der directen Chlorbestimmung im Chlorat enthaltenden Hundeharn nicht zu viel (was der Fall hătte sein müssen, wenn unterschweflige Säure und Sulfocyansâure anwesend gewesen wären), sondern zu wenig $\mathrm{Cl}$ gefunden, ein Verhalten, für welches Dr. Kimmyser keine genügende Erklärung hat ausfindig machen können, und welchem v. Mering nicht begegnet zu haben scheint, da er in seinen genannten Versuchen die Chloride im Hundeharn auch durch die directe $\nabla 011$ hard'sche Methode bestimmte. 


\begin{tabular}{|c|c|c|c|c|c|c|}
\hline & \multicolumn{2}{|c|}{$\mathrm{NaCl}$} & \multicolumn{2}{|c|}{$\mathrm{NaClO}_{3}$} & \multicolumn{2}{|c|}{ Harnstoff } \\
\hline & inProe. & in $g$ & in Proc. & in $\mathrm{g}$ & in Proc. & in $\mathrm{g}$ \\
\hline 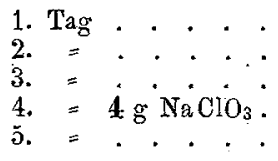 & $\begin{array}{l}1,08 \\
1,24 \\
1,10 \\
1,26 \\
1,14\end{array}$ & $\begin{array}{l}12,312 \\
12,648 \\
12,540 \\
13,104 \\
11,514\end{array}$ & $\begin{array}{c}\overline{-} \\
\overline{-} \\
0,219 \\
\text { qualitativ }\end{array}$ & $\begin{array}{c}- \\
- \\
2,277 \\
\text { chweisbar }\end{array}$ & $\begin{array}{l}4,46 \\
4,86 \\
4,88 \\
5,1 \\
5,36\end{array}$ & $\begin{array}{l}50,8 \\
49,4 \\
55,6 \\
53,0 \\
54,136\end{array}$ \\
\hline
\end{tabular}

Aber damit steht die Thatsache durchaus nicht im Einklang, dass am folgenden Tage eine unverkennbare Abnahme des $\mathrm{Cl}$ im Harn gefunden wird, obgleich das Chlorat sich noch dentlich im Harn nachweisen lässt. Es ist doch, wenn wirklich Chlorat zu Chlorid reducirt wird, durchaus nicht einzusehen, weshalb die Cl-Ausscheidung am 2. Tage abnimmt, da ja doch noch Chlorat im Organismus circulirt und dieses Chlorat zu Chlorid reducirt werden kann. Diese Cl-Abnahme am Tage nach dem Chloratgebrauch, welche sich, wie wir sehen werden, in fast allen Versuchen mit derselben Constanz wiederholt, macht es zweifelhaft, ob die am Tage des Chloratgebrauches sich einstellende Cl-Zunahme wirklich von dem reducirten Chlorat abbängig gestellt werden muss. Stammte jedoch das an diesem Tage mehr ausgeschiedene $\mathrm{Cl}$ nicht von dem eingeführten Chlorat, sondern von dem Körper selbst her, so wäre damit für die nachfolgende $\mathrm{Cl}$-Abnahme eine genügende Erklärung gefunden, da bei unveränderter Zufuhr nur auf diese Weise sich das Cl Na-Gleichgewicht herstellen kann.

Die folgenden Versuche betreffen eine Hündin, welche während derselben immer die nämliche Nahrung erhielt und zur Gewinnung des Harns regelmässig katheterisirt wurde. Bei diesem Thier wnrden 3 Versuchsreihen angestellt, von welchen ich hier nur zwei mittheile, und zwar eine, in welcher das Natriumchlorat innerlich verabreicht wurde, und eine, in welcher das Salz subcutan injicirt wurde. Die folgende Tabelle (S. 174) bezieht sich auf den mit innerlicher Darreichung angestellten Versuch.

In diesem Versuche wird fast die ganze eingeführte Chloratmenge wieder als solche mit dem Harn ausgeschieden (3,618 von $4 \mathrm{~g})$. Dennoch zeigt sich auch hier am Tage der Chlorateinnahme eine relativ beträchtliche Vermehrung der Chlorausscheidung, diese kann also unmöglich vom reducirten Chlorat herrihren. Vielmehr wird es durch die wieder am folgenden Tage sich einstellende Verminderung der Chlorausscheidung in hohem Maasse wabrscheinlicb, 


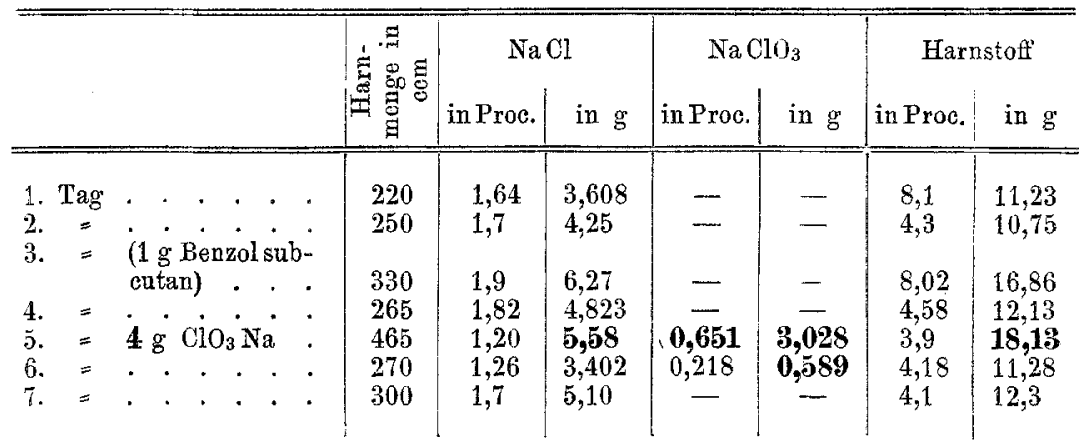

dass dieses Plus an Chlor vom Organismus selbst hergenommen ist und mit der Reduction von Chlorat nichts zu schaffen hat. Dafür spricht noch ganz besonders der Umstand, dass an demselben Tage, an welchem die verminderte Chlorausscheidung sich einstellt, noch eine ganz beträchtliche Menge Chlorat im Körper circulirt.

Der 2. Versuch, den ich hier mittheilen will, bezieht sich auf eine subcutane Injection ron Natriumchlorat.

\begin{tabular}{|c|c|c|c|c|c|c|c|c|}
\hline & & \multirow{2}{*}{ 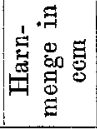 } & \multicolumn{2}{|c|}{$\mathrm{NaCl}$} & \multicolumn{2}{|c|}{$\mathrm{NaClO}_{3}$} & \multicolumn{2}{|c|}{ Harnstoff } \\
\hline & & & in Proc. & in $g$ & in Proc. & in $\mathrm{g}$ & in Proc. & in $\mathrm{g}$ \\
\hline $\begin{array}{l}\text { 1. Tag } \\
2 . \quad=\end{array}$ & sube. Injection & 302 & 1,54 & 4,65 & - & - & 2,2 & 6,644 \\
\hline $\begin{array}{l}3 .= \\
4 .=\end{array}$ & $\begin{array}{ccccc}\mathrm{v} . & \mathrm{g} & \mathrm{NaClO}_{3} \\
\cdot & \cdot & \cdot & \cdot & \\
. & \cdot & . & \cdot & .\end{array}$ & $\begin{array}{l}328 \\
412 \\
340\end{array}$ & $\begin{array}{l}1,10 \\
1,74 \\
1,70\end{array}$ & $\begin{array}{l}3,608 \\
7,168 \\
5,78\end{array}$ & $\begin{array}{c}0,474 \\
- \\
-\end{array}$ & $\frac{1,554}{-}$ & $\begin{array}{l}2,4 \\
2,7 \\
3,2\end{array}$ & $\begin{array}{l}7,872 \\
11,124 \\
10,88\end{array}$ \\
\hline
\end{tabular}

Dieser Versuch zeigt gewissermaassen einige Abweichungen von den Resultaten, welche sich bei fast allen anderen Versuchen ergaben. Obgleich eine gewisse Menge des eingeführten Chlorats im Harn nicht als solche zurïckgefunden wird, und obgleich die Reductionstheorie und die bei anderen Versuchen gewonnenen Erfahrungen am Tage dieser Chlorateinfithrung eine Vermehrung der Chlorausscheidung erwarten lassen, so zeigt die Cl-Ausscheidung sich im Gegentheil vermindert. Es ist dann auch dieser Versuch nicht als ein kunstgemässer zu betrachten, da die Hündin kurz nach der subcutanen Injection unter heftig zitternden Bewegungen zu fiebern anfing und dieses Fieber sich erst 16-18 Stunden nach Anfang des Versuches legte. Jedenfalls aber ist aus diesem Versuch durchaus kein Argument für die Richtigkeit der Reductionstheorie abzuleiten. 
Die Mehrzahl der von Dr. Kimmyser gemachten Versuche wurde bei Kaninchen angestellt, und da eben über die Verhältnisse der Chloratausscheidung bei diesen Thieren ${ }^{1)}$ keine Versuche gemacht oder beschrieben worden sind, so wird auf diese Weise eine gewisse Lücke ausgefüllt. Für die Versuche wurden fast nur männliche Thiere genommen, welche leicht katheterisirt werden konnten und regelmässig jeden Tag dieselbe Menge Milch mit Mehl durch die Oesophagussonde erhielten.

Der erste hier mitzutheilende Versuch betrifft ein Thier, welches 2 mal einige Tage hintereinander Natriumchlorat per os erhielt.

Kaninchen, $2500 \mathrm{~g}$.

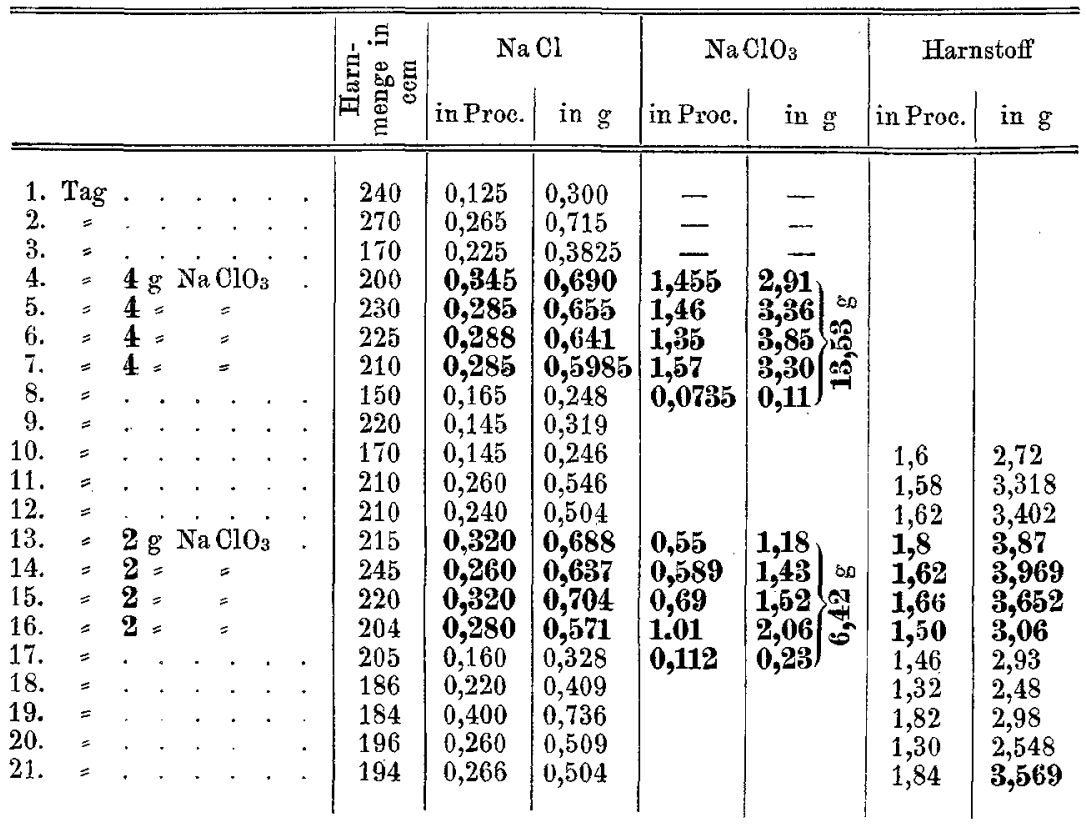

Die Resultate dieses Versuches stimmen wieder mit den früher erhaltenen überein. Von dem einige Tage nach einander eingeführten Chlorat findet sich bei Weitem die grösste Menge in dem Harn wieder und es zeigt der Verlanf der Ausscheidung, indem sie bei gleichen Dosen allmählich ansteigt, an einem einzelnen (16.) Tage die eingeführte Dose übertrifft und jedesmal die Einfuhr überdauert, dass das Chlorat ziemlich lange im Organismus circulirt. Während

1) Die genauen Versuche und Bestimmungen v. Mering's beziehen sich z. B. nur auf Hunde. 
der Chlorateinnahme ist die Chlorausscheidung constant vermehrt, und zwar vollkommen unabhängig von der eingeführten Dose des Chlorats, da sie sowohl bei 2 wie bei $4 \mathrm{~g}$ täglich fast dieselben Zahlen darbietet, wie sich aus folgender Zusammenstellung ergibt.

( $\mathrm{NaCl}$-Chlorausscheidung bei Einfuhr von

\begin{tabular}{|c|c|c|}
\hline $\begin{array}{c}\mathbf{4} \mathbf{g} \\
0,690 \\
0,655 \\
0,641 \\
0,5985 \\
\end{array}$ & und & $\begin{array}{l}2 \mathrm{~g} \text { Chlor } \\
0,688 \\
0,637 \\
0,704 \\
0,571 \\
\end{array}$ \\
\hline 2,5845 & & 2,600 \\
\hline
\end{tabular}

Nach dem Aufhören der Chloratverabreichung ergibt sich weiter constant eine deutliche Abnahme der Chlorausscheidung, obgleich noch stets Chlorat mit dem Harn ausgeführt wird.

Die anderen Versuche mit innerlicher Anwendung des Chlorats übergehe ich, ihre Resultate sind ganz übereinstimmende; nur reihe ich hier noch eine Tabelle an, welche sich auf die Verhältnisse der Chlor- und Chloratausscheidung nach der subcutanen Injection von Natriumchlorat beim Kaninchen ergibt.

Kaninchen, $1900 \mathrm{~g}$.

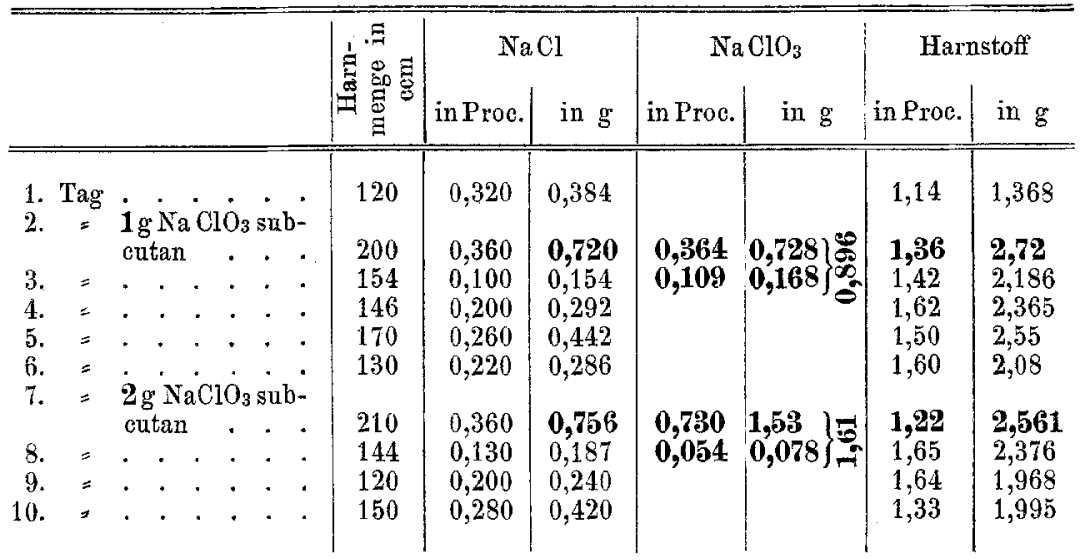

Man sieht, dass irgend ein bedeutender Unterschied zwischen dem Verhalten der Chlorat- und Chlorausscheidung bei der subeutanen Injection und demjenigen bei der innerlichen Verabreichung nicht besteht. Auch hier wird wieder fast die ganze Menge des eingeführten Chlorats ausgeschieden, auch hier ist wieder die Vermehrung der $\mathrm{Cl}$-Ausscheidung ganz unabhängig von der angewandten Dosis, nach $1 \mathrm{~g}$ ebenso gross wie nach $2 \mathrm{~g}$, auch hier zeigt sich wieder die Abnahme der Chlorausscheidung am Tage nach der Einfiihrung des 
Chlorats, an einem Zeitpunkte, an welchem noch eine gewisse Menge Chlorat als solches im Organismus circulirt.

Wie miissen nun die erhaltenen Resultate gedeatet werden? Die Antwort ist nicht schwierig.

Das Deficit an Chlorat im Harn, welehes sich fast in allen Versuchen, obgleich in einigen auf recht unbedeutende Weise, vorfindet, darf ruhig zum Theil auf Rechnung von Ungenauigkeiten in der Bestimmung des Chlorats, in der Ansammlung des Harns u. s. w. gestellt werden. Theilweise hängt es aber mit dem Umstand zusammen, dass der Harn 1 oder 2 Tage nach der Verabreichung des Ghlorats noch immer deutliche Spuren dieser Substanz enthält, und dass diese kleinen Mengen, welche auch im Speichel und anderen Körperflüssigkeiten aufgefunden werden können, sich der quantitativen Bestimmung entziehen. Wie die französischen Forscher es schon früher dargethan haben und wie auch $\nabla$. Mering dies bestätigt hat, so wird selbst nach der Verabreichung sebr kleiner Mengen Chlorats diese Substanz unverändert im Harn, im Speichel u. s. w. wiedergefunden, und bei der Zufuhr grösserer Mengen wiederholt sich diese Erscheinung in dem Sinne, dass 24 Stunden und später nachher der Harn noch immer Chlorat enthält. Endlich kann, wie wir später sehen werden, das Deficit an Chlorat noch einen anderen Grund haben, namentlich denjenigen, dass ein Theil dieser Substanz im ausgeschiedenen und zur Analyse aufbewahrten Harn zu Chorid reducirt worden ist.

Es ist also jedenfalls voreilig, aus dem Deficit von Chlorat, welches ausserdem in einigen Versuchen fast gar nicht vorhanden ist, auf eine Reduetion dieser Substanz im lebendigen Organismus schliessen zu wollen.

Ebensowenig berechtigt die Vermehrung der Chlorausscheidung am Tage der Chloratverabreichung zu diesem Schluss. Dr. Kimmyser fand sie in seinen Versuchen fast ganz unabhängig von der eingeführten Dose und bei demselben Thiere innerhalb enger Grenzen, selbst bei verschiedenen Dosen wenig wechselnd. Sie kann, wie schon Is a mbert angegeben hat, ihren Grund haben in den eigenthümlichen Diffusions- und Secretionsverbältnissen des Harns und vielleicht so zu Stande kommen, dass die Ausscheidung irgend eines leicht diffundirenden Salzes zu gleicher Zeit einen stärkeren Kochsalzstrom, d. h. eine vermehrte Cl Na-Ausscheidung vermittelt. Wäre von Dr. Kimmyser in seinen Versuchen Kaliumchlorat angewandt, so wäre diese vermehrte $\mathrm{Cl} \mathrm{Na}$-Ausscheidung nach den Versuchen Bunge's selbstverständlich, da ja durch den Genuss von Kalisalzen 
dem Organismus Chlornatrium entzogen werden soll, Da hier aber nur Natriumchlorat zur Anwendung gekommen war, so hat Dr. Ki m myser einen Versuch ad hoc mit einem Natronsalz (Natriumnitrat) gemacht, unter Umständen, welehe zu gleicher Zeit noch eine nähere Auskunft über die bezüglichen Fragen versprachen.

Zu ungefähr derselben Zeit wurden 2 Kaninchen der Inanition unterworfen. Die Inanition wurde so lange fortgesetzt, bis der Harn kein Chlor mehr enthielt. Dann wurden dem einen Kaninchen $4 \mathrm{~g}$ Natriumchlorat, dem anderen $4 \mathrm{~g}$ Natriumnitrat in $100 \mathrm{cem}$ Wasser verabreicht. Bei beiden zeigte sich nun eine relativ sehr bedeutende OINa-Ausscheidung. Der Harn des Chloratkaninchens enthielt 0,4726 , derjenige des Nitratkaninchens $0,406 \mathrm{~g} \mathrm{NaCl}$. Am darauffolgenden Tage - die Thiere blieben hungernd - war das $\mathrm{Cl}$ wieder ganz aus dem Harn der beiden Versuchsthiere geschwunden, obgleich sich in dem Harn des Chloratthieres noch deutlich unzersetztes Chlorat auffinden liess. Von den $4 \mathrm{~g}$ : verabreichtem $\mathrm{NaClO}_{3}$ wurden innerhalb der ersten 24 Stunden wieder $3,18 \mathrm{~g}$ als solches mit dem Harn entfernt.

Wenn nun selbst in einem kochsalzarmen Organismus, wie demjenigen eines hungernden Thieres, die Ausscheidung eines leicht diffundirenden Natronsalzes einen vermehrten Kochsalzstrom nach dem Harn veranlasst, so muss a fortiori bei den gut geftutterten, so viel wie möglich auf Kochsalzgleichgewicht sich befindenden Thieren auch nach der Einfuhr von Natriumchlorat eine vermehrte Cl Na-Ausscheidung folgen. Es gibt also der Organismus von seinem eigenen Chlornatriumbestand ab, wenn die Ausscheidung einer grossen Menge des. Chlorats erfolgen soll, und deshalb ergibt sich auch so constant am Tage nach dieser Ausscheidung eine Beschränkung der $\mathrm{Cl} \mathrm{Na-Ausfuhr.}$ Dass diese Auffassung die richtige ist, wird unter Anderem auch dadurch bestätigt, dass, wenn dem Körper mebr ClNa zugeführt wird und dieser sich übrigens in $\mathrm{ClNa-Gleichgewicht} \mathrm{befindet,} \mathrm{nichts} \mathrm{Der-}$ artiges beobachtet wird. Die mehr eingeführte $\mathrm{ClNa-Menge} \mathrm{wird,}$ wie Dr. Kimmyser das noch in einem besonderen Versuche dargethan hat, einfach innerhalb zweimal 24 Stunden wieder ausgeschieden und von einer darauf folgenden Beschränkung der Cl-Ausfuhr ist keine Rede. Hätte also der Kochsalzbestand des Organismus durch Reduction des eingeführten Chlorats bei den Versuchsthieren zugenommen, so bätte diese Beschränkung der $\mathrm{Cl} \mathrm{Na-Ausscheidung} \mathrm{sich}$ nicht zeigen können. Da diese aber in allen Versuchen beobachtet ist, so kann der ClNa-Bestand des Körpers nicht zugenommen haben und ist also von einer nachweisbaren Reduction des Na-Chlorats in $\mathrm{Na}-\mathrm{Cl}$ im Organismus selbst nichts zu bemerken.

Die von Dr. Kimmyser in seiner Dissertation mitgetheilten 
Versuche und ihre Resultate stimmen, ich möchte fast sagen, bis anf ein Haar iiberein mit den Resultaten, welche Dr. v. Mering in seiner Monographie uber diesen Gegenstand mitgetheilt hat. Sie bringen eine vollkommene Bestätigung der von Is ambert und $\mathrm{Ra}$ butea u uber denselben Gegenstand gewonnenen Erfahrungen.

Diese Uebereinstimmung in den Versuchsresultaten verhindert aber nicht, dass die verschiedenen Forscher zu ganz entgegengesetzten Schlussfolgerungen kommen. Is a m bert und Rabutea u leugnen auf Grund ihrer Versuche das Bestehen jedweder Reduction des Chlorats im lebenden Organismus, Dr. Kimmyser spricht sich etwas vorsichtiger aus, indem er schliesst: Das Bestehen einer Reduction des Chlorats in Chlorid im lebendigen Organismus kann nicht als bewiesen betrachtet werden und wenn überhaupt eine Reduction stattfindet, betrifft diese jedenfalls so kleine Mengen des eingeführten Salzes, dass sie sich der exacten Bestimmung ganz entzieht. Dr. v. Mering aber kommt zu einem anderen Schluss, wozu er nicht dureh seine Untersuchungen über die Chloratausscheidung, sondern durch eine damit nicht direct zusammenhängende Erscheinung gefübrt wird. Er sagt wörtlich (l. c. S. 74 und 75): „Meine Versuche zeigen, dass der weitaus grösste Theil von einverleibtem Kali chloricum im Urin unverändert erscheint, und es wiìde, wenn das Kali chloricum (Chlorat) nicht ein so höchst eigenthümliches Verhalten zum Blute zeigte, der Schluss unbedingt gerechtfertigt sein, dass dasselbe den Organismus in seiner Totalität unverändert passire ......" „Trotzdem aber, dass nach Zufuhr von $1 \mathrm{~g}$ chlorsaurem Kali $0,91 \mathrm{~g}$ wiedergefunden wurden (vgl. Kimmyser's Versuch), trotzdem, dass nach Einfuhr von $0,05 \mathrm{~g}$ im Urin und Speichel Chlorsäure deutlich nachweisbar ist, müssen wir mit Rücksicht darauf, dass lebendes Blut Chlorate reducirt, den Satz aufstellen, dass das Kali chloricum eine theilweise Reduction im Organismus erleidet." Und an einer anderen Stelle (S. 140) relevirt er, dass die Versuche iber die Ausscheidung des chlorsauren Kali zu der Schlussfolgerung drängen, dass diese Substanz durch den Urin völlig ausgeschieden werde. Dennoch nehme er an, dass das chlorsaure Kali (das Chlorat) bei seinem Durchgang durch den Organismus auch stets eine Reduction erleide, da das Salz vor seiner Ausscheidung die Blatbahn passiren müsse und Blut chlorsaures Kali nachweisbar reducire. Es gipfelt also die ganze Schlussfolgerung v. Mering's immer wieder in einem Argument, welches unbedingt als sehr schwerwiegend betrachtet werden kann, aber durchaus nicht 
dem Verhalten der Chloratausscheidung selbst entlehnt und anderswo hergenommen ist. Mit den anderen Forsehern stimmt Dr. v. Mering darin überein, dass die Versuche uiber Chloratausscheidung an und fir sich durchaus nicht zu der Annahme einer Rednction im lebenden Körper berechtigen, aber weil das Verhalten des Chlorats zum Blut nicht zu diesem Ergebniss stimmt, wird der unverkennbare Widersprach zwischen den beiden Reihen von Versuchsresultaten so gelöst, dass dennoch auch bei der Chloratausscheidung eine partielle Reduction angenommen wird, auf welche aber aus den Versuchen selbst nicht geschlossen werden kann.

Um nun aber den Versuchsresultaten über die Chloratausscheidung keine Gewalt anzuthun, muss wieder angenommen werden, dass es mit dieser partiellen Reduction eine ganz eigene Bewandtniss hat. Die Physiologie lehrt, dass chemische Substanzen, welche eine Umsetzung im lebenden Organismus erfahren, dennoch unverändert im Harn erscheinen können, wenn sie in grossen Mengen eingefiihrt worden sind. Es reicht bei diesen grossen Mengen so zu sagen das vorhandene Protoplasma nicht aus und ein grösserer oder geringerer Theil verlässt den Körper unverändert, ohne den Einfluss des Protoplasma erfahren zu haben. Bei den Chloraten muss nun gerade das Umgekehrte der Fall sein, wenn man die Versuchsergebnisse über Chloratàusscheidung mit dem Bestehen einer Reduction im Einklang bringen will. Sie sollen das höchst eigenthümliche und von allen sonstigen Erfahrungen vollkommen abweichende Verhalten zeigen, dass sie in kleinen Mengen von dem lebenden Körper gar nicht angegriffen werden, dagegen wohl, wenn sie in sehr grossen Mengen demselben zugefiuhrt worden sind.

Es tritt nun die Frage an uns heran, ob es denn wirklich zwischen diesen einander widersprechenden Resultaten keinen anderen Ausweg: gibt, und ob die daraus sich ergebenden und von vornherein wenig befriedigenden Erklärungen nicht umgangen werden kömen, mit anderen Worten, die Frage erheischt die Antwort, ob denn wirklich die Reduction der Chlorate durch das lebende Blut so iiber allen Zweifel erhaben ist. Wenn man bedenkt, dass aus den Versuchen am lebenden Körper selbst, soweit sie die Chloratausscheidung betreffen, das Bestehen dieser Reduction nicht abgeleitet werden kann, wenn man bedenkt, dass in diesen Versuchen das Chlorat das lebende Blut passirt haben muss, am in den Harn zu gelangen, dass dabei besonders in den Versuchen von Dr. v. Mering selbst sebr grosse Mengen (z. B. $100 \mathrm{~g}$ in 5 Tagen) mit dem lebenden Blut in Beruibrung gewesen sind, ohne dass sich eine nachweisbare Reduction hat auffinden 
lassen, wenn man weiter bedenkt, dass das Bestehen der Reduction sich hauptsächlich aus Thatsachen ergibt, welche bei Versuchen mit Blut ausserhalb des Körpers, bei Sectionsresultaten und bei Intoxicationsversuchen gewonnen wurden, so ist der soeben ausgesprochene Zweifel ein vollkommen berechtigter. Um aber der Sache näher zu kommen, müssen wir die letztgenannten Thatsachen genauer betrachten und wir glauben dies am besten thun zu können, wenn wir erstens die Reduction der Chlorate durch thierische Fliissigkeiten und organische Substanzen einer Besprechung unterziehen und uns dann erst zu den Intoxicationsversuchen, den Sectionsresultaten u. s. w. wenden.

II. Die Reduction der Chlorate durch organische und organisirte Substanzen und durch thierische Flüssigkeiten ausserhalb des lebenden Organismus.

Im Laufe der Zeit sind Chlorate öfters mit organischen und organisirten Substanzen, thierischen Flüssigkeiten $\mathfrak{u}$. s. w. bei Zimmeroder Körpertemperatur mit einander in Berührung gebracht worden, um die Frage zu entscheiden, welche Substanzen eine Reduction der chlorsauren Salze bewirken. Von keinem Forscher ist dies mit mehr Geschick und Fleiss geschehen, wie von v. Mering, welcher ganz vorwurfsfreier Methoden sich bediente und seine Versuche mannigfach modificirte.

Von organischen Substanzen sind auf ihr Vermögen, Chlorate zu reduciren, soweit ich habe erfahren können, folgende Bestandtheile des thierischen Körpers geprüft:

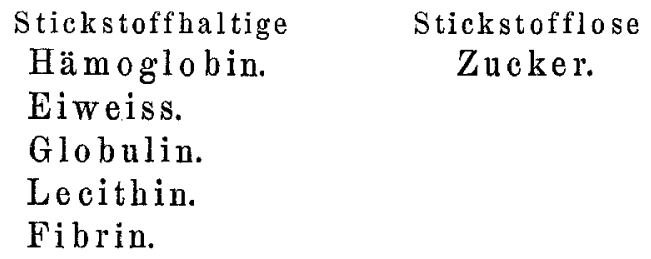

Lassen wir das Hämoglobin für einen Augenblic̣ bei Seite, so können wir dreist behaupten, dass keine einzige dieser Substanzen im frischen Zustande im Stande ist, Chlorate zu reduciren.

Fuir das $\mathrm{Eiweiss}$ ist dies schon vor vielen Jahren durch Milon dargethan, für das Globulin und Lecithin durch Versuche, welche wir v. Mering (l. c. S. 123 und 129) verdanken und wobei entweder quantitativ oder qualitativ festgestellt wurde, dass von einer Reduction der Chlorate unter dem Einflusse dieser Eiweissstoffe keine Rede ist. 
Nur in Bezug auf das Fibrin bestehen ziemlich bedeutende Meinungsunterschiede. Während Milon auch dem Fibrin einen reducirenden Einfluss auf Chlorate absprach, behauptete Binz vor einigen Jahren, dass diese Substanz das in Wasser gelöste chlorsaure Kali bei Zimmer- bis Blutwärme seines Sanerstoffs beraube. Er sagt aber gleich dazu, dass dies besonders raseh geschieht, wenn diese Substanz in Fäulniss ibergeht. v. Mering hat die Versuche Binz's wiederholt und kommt (1. e. S. 128 und 130) zu dem Schluss, dass die Chlorate nur dann ihres Sauerstoffs beraubt werden, wenn sie mit faulendem Fibrin zusammengebracht sind. Frisches Fibrin dagegen lässt die Chlorate, nach seinen Versuchen, welche als beweisend betrachtet werden können, vollkommen unverändert, selbst bei Bluttemperatur.

$\mathrm{Da}$ auch $\mathrm{Zucker}$ keinen reducirenden Einfluss auf Chlorate ausübt, wie dies ebenfalls von $\mathbf{v}$. Mering dargethan ist, so bleibt von allen chemischen Bestandtheilen des Körpers; welche darauf untersucht sind, nur das Hämoglobin als die einzige Substanz ïbrig, welche im Stande zu sein scheint, den Chloraten Sauerstoff zu entziehen.

Wie steht es nun mit den organisirten Substanzen und ihrer reducirenden Wirkung auf Chlorate? Nur zwei dieser Substanzen, der Eiter und die Bierhefe, sind auf diese Wirkung untersucht. Von beiden hat $\mathrm{Binz}$ behauptet, dass sie diese Wirkung ausüben. Auch hier scheint dies nur der Fall zu sein, wenn Fäulniss dabei auftritt. Was den Eiter anlangt, so hat wieder v. Mering (Versuch 115, S. 129) gezeigt, dass frischer Eiter selbst in 3 Tagen keine Zersetzung des zugefügten Chlorats bewirkt. Ueber den Einfluss von Bierhefe gibt es mehrere Untersuchungen. Hirne hat im Jahre 1875 gezeigt, dass Kaliumchlorat, mit Zucker und Amylum zusammengebracht, welehe man 8 Stunden lang auf $41^{\circ} \mathrm{C}$. durch Bierhefe gäbren liess, durchans keine Zersetzung durch diese Fermentation erfuhr. Während Kosegarten und Wernicke weiter feststellten, dass chlorsaures Kali die Wirkung von Hefe auf Zucker in keiner Weise behindere, hat nun Binz behauptet, dass auch frische Bierhefe im Stande ist, Chlorat zu reduciren. Er selbst macht aber die Bemerkung, dass die Sauerstoffentziehung selbst bei stark fortschreitender Fäulniss sich hier weniger energisch gestaltete, als bei der Fäulniss des Fibrins. v. Mering hat dann die Versuche wieder aufgenommen und das Resultat seiner Untersuchungen bestätigte vollkommen die älteren Hirn e'schen Angaben, indem er fand, dass chlorsaures Kali weder in Berührung mit frischer Hefe noch bei der 
alkobolischen Gährung des Zuckers eine Reduction erleidet (1. e. S. 128).

Aus diesen Versuchen darf man ohne Zweifel schliessen, dass weder organische Bestandtheile des Körpers noch organisirte protoplasmahaltige Substanzen im Stande sind, den Chloraten Sauerstoff zu entziehen, so lange sie vollkommen frisch und unzersetzt sind, dass aber eine Reduction der Chlorate sofort eintritt, sobald die betreffenden Substanzen in Fäulniss tibergehen.

Es ertbrigt noch, den Einfluss einzelner thierischer Flïssigkeiten auf die Reduction von Chloraten zu besprechen. Ganz kurz sei hier erwähnt, dass weder frisches farbloses Blutserum noch frische Ascitesflüssigkeit, mit welchen v. Mering experimentirte, Chlorate zu reduciren im Stande sind. Dagegen gibt es zwei andere Fliussigkeiten, welche diese Eigenschaft in eminenter Weise besitzen, ich meine den Harn und das Blut.

Dr. Kimmyser hat in seiner Inaugural-Dissertation es sich besonders angelegen sein lassen, den reducirenden Einfluss des frisch gelassenen Harns auf Chlorate näher zu prüfen. Er kam auf diesen Gedanken, nicht allein weil jeder Harn reducirende Substanzen enthält, sondern auch weil in fast allen seinen Versuchen über Chloratausscheidung ein unerklärliches Deficit an Chlorat vorhanden war, und besonders, weil aus den von mir in Gemeinsehaft mit van de Velde iiber die Zersetzung der Hippursäure angestellten Untersucbungen ${ }^{1)}$ hervorgegangen war, wie schnell Fäulnisserseheinungen und Zersettzungen in augenscheinlich ganz frischem Harn auftreten. Schon der erste diesbezügliche Versuch ergab deutlich positive Resultate, sowohl mit Menschen- wie mit Kaninchenharn. Nur mit Hundeharn wurden zweifelhafte Resultate erzielt, welche aber vielleicht durch die Sehwierigkeiten bewirkt sein können, denen wir bisweilen bei der Bestimmung der Chloride und Chlorate im Hundeharn begegnen.

Die erhaltenen, in der folgenden Tabelle abersichtlich zusammengestellten Resultate sind so gewonnen, dass in jedem Harn eine doppelte Chlorbestimmung vor und nach dem Zusatz von Chlorat gemacht und ans der Differenz die reducirte Chloratmenge berechnet wurde. Meistens wurde das Chlorat nach dem Versuch auch noch besonders bestimmt, um zu sehen, ob das unveränderte und das reducirte Chlorat mit der ursprünglich zngesetzten Menge stimmte.

1) Stokvis und yan de VeIde, Dieses Archiv, XVII. Bd. S. 189. 
Reduction des Natriumchlorats durch Harn.

\begin{tabular}{|c|c|c|c|c|c|c|}
\hline Temperatur & $\begin{array}{l}\text { Dauer des } \\
\text { Versuchs }\end{array}$ & 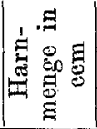 & $\begin{array}{l}\text { Zuge- } \\
\text { setztes } \\
\mathrm{NaClO} 3\end{array}$ & $\begin{array}{l}\text { Reducirt } \\
\text { in } g\end{array}$ & $\begin{array}{l}\mathrm{NaClO}_{3} \\
\text { in Proe. }\end{array}$ & $\begin{array}{l}\text { Nummer des Ver- } \\
\text { suchs u. s. w. }\end{array}$ \\
\hline $\begin{array}{c}\left.37-20^{\circ} \text { C. }{ }^{1}\right) \\
37-20== \\
20== \\
0== \\
20== \\
20== \\
20== \\
20== \\
20== \\
20== \\
20== \\
20==\end{array}$ & $\begin{aligned} 24 \text { Stunden } \\
= \\
= \\
= \\
= \\
= \\
= \\
= \\
= \\
= \\
=\end{aligned}$ & $\begin{array}{l}50 \\
50 \\
50 \\
50 \\
50 \\
50 \\
50 \\
50 \\
50 \\
50 \\
50 \\
10\end{array}$ & $\begin{array}{l}0,500 \\
0,500 \\
0,500 \\
0,500 \\
0,500 \\
0,500 \\
0,500 \\
0,500 \\
0,500 \\
0,500 \\
0,500 \\
0,100\end{array}$ & $\begin{array}{l}0,067 \\
0,122 \\
0,087 \\
0,00 \\
0,047 \\
0,00 \\
0,024 \\
0,120 \\
0,00 \\
0,024 \\
0,036 \\
0,00\end{array}$ & $\begin{array}{c}13,4 \\
24,4 \\
17,4 \\
0,0 \\
8,4 \\
0,0 \\
4,8 \\
24 \\
0,0 \\
4,8 \\
7,2 \\
0,0\end{array}$ & $\begin{array}{l}\left.\text { 1. K. }{ }^{2}\right) \\
\left.\text { 2. M. }{ }^{3}\right) \\
\text { 3. M. } \\
\text { 4. M. } \\
\left.\text { 5. M. }+^{4}\right) \\
\text { 6. M. S.5) } \\
\text { 7. M. N.6) } \\
\text { 8. M. A.7) } \\
\text { 9. M. S. }+ \\
\text { 10. M. N. }+ \\
\text { 11. M. A. t } \\
\text { 12. K. S. }\end{array}$ \\
\hline
\end{tabular}

1) Wäbrend 6 Stunden auf $37^{\circ} \mathrm{C}$. erhitzt, dann bei Zimmertemperatur $\left(20^{\circ}\right)$ aufbewahrt. 2) $\mathrm{K}$. = Kaninchenharn. 3) $\mathrm{M}$. = Menschenharn. 4) + bedeutet, dass der Harn vor dem Versuch während 1/4-1/2 Stunde ausgekocht wurde. 5) S. = Säurereaction. 6) $\mathrm{N}$. = Neutrale Reaction, bewirkt durch genaues Titriren mit Normalnatronlösung. 7) $\mathrm{A} .=$ Alkalische Reaction, ebenso dureh zugesetzte Normalnatronlösung bedingt.

Man ersieht aus der Tabelle, dass selbst 24 Stunden und Zimmertemperatur genügen, um fast den vierten Theil des dem Harn zugesetzten Natriumchlorats seines Sauerstoffs zu berauben (Versuch 2 und 8). Die Intensität der Reduction ergibt sich dabei als abbängig 1. von der Temperatur (da sie bei einer Temperatur von $0^{\circ} \mathrm{C}$. ganz ausbleibt und bei Blutwärme böher ausfällt wie bei Zimmertemperatur, Versuch 2, 3 und 4); 2. von der jeweiligen Reaction des Harns, da sie bei saurer Reaction ganz ausgeschlossen scheint, dagegen bei neutraler Reaction und ganz besonders bei alkalischer Reaction deutlich vorbanden ist (Versuch $6,7,8,9,10,11,12$ ), und endlich 3 . von dem Umstand, ob der Harn vor dem Versuch ausgekocht war, da Auskochen während $1 / 4-1 / 2$ Stunde genügte, um die Reduction selbst in alkalischer Flüssigkeit zu beschränken (Versuch 3 und 5, 8 und 9).

Die Bedingungen, welche im Harn die Reduetion des Chlorats begünstigen oder beschränken, sind also vollkommen dieselben als diejenigen, durch welche der Fäulnissprocess im Harn gefördert oder hintangehalten wird. Und obgleich es noch nicht gelungen ist, das dabei wirksame organisirte oder nicht organisirte Ferment zu isoliren, so geht man doch gewiss nicht fehl, wenn man die Reduction des Chlorats, welche in sich selbst überlassenem Harn zu Stande kommt, als einen Ausdruck der in dieser Flüssigkeit vor sich gehenden Fäulniss betrachtet. Dass nun sowohl bei Fäulniss des Harns, 
als bei Fäulniss von eiweisshaltigen Flüssigkeiten (Eiter, Fibrin) das darin anwesende Chlorat ganz oder zum Theil reducirt wird, kann kein Wunder nehmen, da ja der chemische Process der Fäulniss sich besonders durch das Auftreten ron Reductionen charakterisirt.

Die uns hier aber am meisten interessirende Reduction der Chlorate, welche durch thierische Flüssigkeiten bewirkt wird, ist diejenige, welche unter dem Einflusse des Blutes za Stande kommt und wobei das Blut selbst sehr auffällige Veränderungen zeigt. Der Erste, welcher diese Veränderungen beobachtet und beschrieben hat, obne jedoch die Bedeutung derselben zu erkennen, war Is ambert. Er sah das mit einer Lösung von Kaliumchlorat gemischte Aderlassblut nach einiger Zeit dunkel werden und sich schliesslich in eine braunschwarze (noirâtre) feste Masse verwandeln. Dann zeigte Jäderholm, dass im Widerspruch mit der Aussage Preyer's, welcher das Kaliumchlorat als ein indifferentes Salz gegenïber Blut betrachtete, durch die Einwirkung dieser Substanz auf Blut Methämoglobin gebildet wird. Darauf erschien die epochemachende Arbeit Marchand's, welche die im Laufe der Zeit fast ganz in Vergessenheit gerathene giftige Wirkung der Chlorate - Kali chloricum und Natron chloricum - wieder in überzeugender Weise darthat. In dieser Arbeit wird die Veränderung, welche das Blut unter dem Einflusse chlorsaurer Salze erfährt, als die Ursache der giftigen Wirkung dieser Salze dargestellt und der Beweis geliefert, dass die Blutveränderung sich nicht auf die Bildung von Methämoglobin beschränkt, sondern sogar so weit geht, dass das Hämoglobin ganz zersetzt wird und freies Hämatin entsteht. Dass bei dieser Blutzersetzung das Chlorat za Chlorid reducirt wird und dass die Blutveränderung nur zu Stande kommt, indem das Chlorat seinen Sauerstoff verliert und dieser an elster Stelle sich fester mit dem Hämoglobin verbindet, wird an mehr wie einer Stelle deutlich von ihm ausgesprochen. Den Beweis aber, dass das Chlorat wirklich zu Chlorid unter dem Einflusse des Blutes reducirt wird, vermag er nicht zu bringen, da die von ihm dazu angewandte Methode, wie v. Mering ${ }^{1}$ ) auseinandersetzt, keine zaverlässige genannt werden kann. Alle Lücken nun, welche sowohl in diesen Untersuchungen, als in den früher angestellten mit Bezug auf die durch Chlorate vermittelte Blutzersetzung und die dadurch zu Stande kommende Reduction der Chlorate noch vorhanden waren, wurden durch v. Mering in seiner verdienstvollen Monographie ausgefüllt. ${ }^{2}$ )

1) 1. c. S. 126 .

2) l. c. Kap. VI und VII. 
Durch eine grosse Anzahl mehrfach abgeänderter Versuche und Bestimmungen, wozu er vollkommen zuverlässige und erprobte Methoden anwandte, stellte el folgende Thatsachen fest, welche ich am besten so resumire, dass ich die darauf bezüglichen, mit fetten Buchstaben gedruckten Sätze seiner Schrift hier wiedergebe:

1. Bei Einwirkung von chlorsaurem Kali (Chlorate) auf Hämoglobin und Blut wird erst Methämoglobin dann Hämatin gebildet, wobei sich das Blut in eine schwarze gallertige, kautschukähnliche, nur in Natronund Kalilauge lösliche Masse verwandelt.

2. Die Blutveränderung durch chlorsaure Salze tritt in der Wärme weit rascher ein, als in der Kälte und ist ferner von der Menge des zugesetzten Salzes abhängig. Bei einer Temperatur von $22^{\circ} \mathrm{C}$. genïgen $0,2 \mathrm{~g}$ und bei einer Temperatur von $37^{0} \mathrm{C} .0,1 \mathrm{~g}$ chlorsaures Kali, um in $100 \mathrm{ccm}$ Blut innerhalb 24 Stunden Methämoglobin zu erzeugen.

3. Von den verschiedenen geprüften chlorsauren Salzen wirkt Ammoniumchlorat energischer als alle anderen, dann folgt chlorsaures Magnesium, Calcium, Strontium, Baryum, Natrium und Kalium, die beiden letzten Salze wirken entschieden am schwächsten.

4. Während die freie Chlorsäure in grösseren Mengen fast augenblicklich eine Zersetzung des Blutes bewirkt, so ist die Wirkung der freien Chlorsäure in schwachen Lösungen dennoch nicht eine plötzliche, sondern bedarf Stunden bis Tage zu ihrer Entwicklung. Da diese Wirkung nicht wesentlich intensiver ist als die des beständigsten chlorsauren Salzes und sich nur hinsichtlich der Zeit Unterschiede ergeben, so muss die Wirkung der chlorsauren Salze auf das Blut als eine Wirkung der freien Chlorsäure aufgefasst werden, welche durch das Hämoglobin in Freiheit gesetzt wird, da es ja auch vom Hämoglobin bekannt ist, dass es kohlensaure Salze zersetzen kann.

5. Blut wird durch chlorsaures Kali bei Gegenwart einer grossen Menge von Kohlensäure weit raseher verändert, als bei Gegenwart von wenig Kohlensäure.

6. Saures Natrinmphosphat in geringer Menge dem mit chlorsaurem Kali gemischten Blut zugesetzt, beschleunigt in ähnlicher Weise wie Kohlensäure die Umwandlung des Hämoglobins beträchtlich.

7. Ein unbedeutender Zusatz von kohlensaurem Natron oder Aetznatron verlangsamt die Zersetzung des Blutes durch chlorsaures Kali bedeutend.

8. Chlorsaures Kali wird im Blut zu Chlorkalium reducirt, obne dass gleichzeitig eine Bildung von Kaliumperchlorat stattfindet. Die Reduction des chlorsauren Kali ist bei gleicher Temperatur und Zeitdauer in erster Linie von der absoluten Menge des vorhandenen Chlorats abhängig.

9. Von allen Blutbestandtheilen ist es nur das Oxyhämoglobin, durch welches chlorsaures Kali reducirt wird.

$\mathrm{Zu}$ diesen Erfahrungen möchte ich mir einige Zusätze erlauben. In allen den mitgetheilten Versuchen wurde zu dem Blut eine bestimmte Menge einer wässrigen Lösung des chlorsauren Salzes gesetzt. 
Es wurde dadurch die Concentration der Blutflissigkeit nothwendigerweise geändert. Obgleich nun auf diese Aenderung der Concentration keine Rücksicht genommen ist und die Möglichkeit also vorhanden war, dass die beschriebene Wirkung mit dem Einflusse zusammenhing, den eine zu diluirte oder zu concentrirte Salzlösung auf die rothen Blutkörperchen und die Abspaltung des Hämoglobins ausibbt, so ist dies jedoch durchaus nicht der Fall; denn in einer Reihe von Versuchen ad hoc hat Herr v. Gorkom in defibrinirtem Rindsblut den nach dem Vorgang meines Collegen Prof. H. de Vries sogenannten isotonischen Coefficient für Natrium und. Kalium chloricum festgestellt und sich überzengt, dass auch in solchen Lösungen, in welchen die Blutkörperchen erhalten bleiben, ohne sich vollkommen zu senken, die Methämoglobin - und Hämatinbildung ganz nach der öfters besehriebenen Weise verlänft. Auch macht es keinen Unterschied, ob Natrium oder Kali chloricum in Substanz oder in wässriger Lösung dem Blute zugesetzt wird.

Zweitens kann ich nach den unter meiner Leitung angestellten Untersuchungen nur bestätigen, dass sowohl die Blutzersetzung als die Reduction des Chlorats ron nichts so sehr wie von der Dauer des Versuchs und der Temperatur abhängig sind. Setzt man eine nicht so grosse Menge chlorsaures Salz zu dem Blut, dass die Blutmenge gegenüber derjenigen des Chlorats verschwindend klein wird, nimmt man also so viel Chlorat, dass der procentische Chloratgehalt der Flüssigkeit nicht höher wie 10 Proc. steigt, so dauert es selbst bei einer Temperatur von $37^{\circ} \mathrm{C}$. immer eine oder mehrere Stunden, bis die charakteristische braunschwarze Färbung des Blutes eintritt und der Methämoglobinstreifen spectroskopisch erkennbar ist. Ja selbst bei Anwesenheit einer sehr grossen Menge des Chlorats stellt die Reaction auch bei Bluttemperatur sich nicht sogleich ein, sondern es vergehen immer mehrere Minuten, bevor sie bemerkbar ist. Werden die Versuche bei Zimmertemperatur angestellt, so treten die Erscheinungen viel langsamer ein, aber auch dann bleiben sie, selbst wenn die Flüssigkeit sebr wenig Chlorat enthält, nicht aus, wenn man nur ruhig abwartet. Je länger der Versuch dauert und je mehr die Temperatur der Bluttemperatur gleichkommt, um so intensiver werden die Erscheinungen und am so mehr Chlorat wird ceteris paribus zu Chlorid reducirt. Dies geht z. B. auch aus folgendem Versuch des Dr. Kimmyser hervor, in welchem Blut von bekanntem Cl-Gehalt mit Natriumchlorat zusammengebracht wird und nach $\mathrm{Be}$ endigung des Versuchs die Chlor - und Chloratmenge bestimmt wurde. Die dabei erhaltenen Resultate gibt folgende Tabelle an: 


\begin{tabular}{l|l|c|c|c}
\hline Temperatur & $\begin{array}{c}\text { Dauer des } \\
\text { Versuches }\end{array}$ & $\begin{array}{c}\text { Blutmenge } \\
\text { in ecm }\end{array}$ & $\begin{array}{c}\text { Zugesetztes } \\
\text { Chlorat in g }\end{array}$ & $\begin{array}{c}\text { Reducirtes } \\
\text { Chlorat in g }\end{array}$ \\
\hline $37^{\circ} \mathrm{C}$. & 24 Stunden & 40 & 1 & 0,258 \\
$37^{\circ} \mathrm{C}$. & $48=$ & 20 & 1 & 0,342
\end{tabular}

Nur muss man, wenn man auch die Versuchsdauer und die Temperatur im Ganzen als die Hauptbedingungen für das Zustandekommen und der Intensität der Reduction des chlorsauren Salzes anerkennt, andererseits zugeben, dass es nur höchst selten und nur bei sehr kleinen Mengen des zugesetzten Chlorats gelingt, die ganze Menge desselben zu reduciren.

Drittens kann ich auf die Erfahrungen v. Mering's uiber den günstigen Einfluss, welchen ein grosser Kohlensäuregehalt auf das Zustandekommen der Erscheinungen ausuibt, noch in so weit ein Streiflicht fallen lassen, als durch Dr. Kimmyser im Anschluss an die Erfahrungen Edlefsen's ${ }^{1}$ ) gerade das Umgekehrte, nämlich die Verlangsamung der Zersetzung unter dem Einflusse eines Sauerstoffstromes durch das Blut, beobachtet ist.

Es wurden zu 2 gleichen Portionen Blut - $40 \mathrm{ccm}$ - je $10 \mathrm{ccm}$ einer 10 proc. Natriumlösung gesetzt und beide Portionen während 7 Stunden auf einer Temperatur von $37^{\circ}$ gehalten. Durch die eine Portion wurde andauernd ein Strom atmosphärischer Luft geführt. Sie blieb während 5 Stunden hellroth und ganz unverändert, während die andere Portion schon nach 1 Stunde die eigenthümliche chocoladenähnliche Farbe des Methämoglobinblutes zeigte. Ungeachtet des fortwährenden Sauerstoffstromes trat aber nach der 5. Stunde auch in der 1. Portion die Zersetzung ein und erreichte nun auch sehr bald dieselbe Intensität wie in der zweiten. Die Bestimmung des reducirten Chlorats lieferte am Ende des Versuches in beiden Portionen folgende Zahlen:

Blutmenge Zuges. Chlorat Reduc. Chlorat

Mit Sauerstoff behandeltes Blut $40 \mathrm{ccm} \quad 1 \mathrm{~g} \quad 0,134 \mathrm{~g}$

Sich selbst überlassenes Blut $40=1=0,118=$

Es zeigen sich also nur unbedeutende Unterschiede in Bezug auf die reducirte Chloratimenge, mit anderen Worten, Sauerstoff, zum Blut gesetzt, verlangsamt das Eintreten der Zersetzung, kann aber das $\mathrm{Zu}$ standekommen derselben ebensowenig wie die Reduction des Chlorats verhindern.

Wenn wir uns nun eine Vorstellung von dem Process, wodurch die Zersetzung des Blutes und die Reduction des Chlorats stattfindet

1) Verhandl. des III. Cougresses für innere Mediciu. 1884. S, 364. 
zu machen suchen, so begegnen wir an erster Stelle der Auffassung, dass das Hämoglobin dabei die primärr wirksame Substanz sei, durch welche die Chlorsäure aus dem Chlorat abgespaltet würde. Wäre diese Vorstellung richtig; so müsste ceteris paribus von dem Chlorat um so mehr reducirt werden, je mehr Hämoglobin die Flüssigkeit enthält. Aus den Untersuchungen v. Mering's, welche hieriiber in seiner Tabelle $\mathrm{X}$ enthalten sind, aber von ihm zu einem ganz anderen $Z$ weck benutzt werden, wollen wir nur einige herausnehmen, in welchen in der That diese Verhältnisse obzuwalten scheinen.

Ich wähle z. B. die Versuche 81 and 98. Beide danern 20 Stunden, in beiden beträgt die Temperatur $22^{\circ} \mathrm{C}$. In Versuch 81 werden $20 \mathrm{ccm}$ Blut gebraucht. Von dem zugesetzten Kaliumchlorat werden $96 \mathrm{mg}$ reducirt, d. h. also 9,6 Proc. der zugesetzten Menge in einer Flüssigkeit mit einem Chloratgehalt von $2 \frac{1}{2}$ Proe. In Versuch 98 kommen $100 \mathrm{cem}$ Blut zur Anwendung, das zugesetzte Kaliumchlorat beträgt $500 \mathrm{mg}$, von welchen $90 \mathrm{mg}$ reducirt werden, d. h. also in einer Flüssigkeit von nur 0,45 Proc. Chlorat werden doppelt so viel wie in Versuch 81 reducirt, nämlich 18 Proc. Versuch $\mathbf{8 2}$ und $\mathbf{9 0}$ liefern noch deutlichere Unterschiede: In Versuch 82 (Temperatur $25^{\circ} \mathrm{C}$., Versuchsdauer 40 Stunden) werden in einer Flïssigkeit, welche aus $10 \mathrm{ccm}$ Blut und $10 \mathrm{ccm} 5$ proc. Kaliumchloratlösung (21/2 proc. Chloratlösung) besteht, $115 \mathrm{mg}$ Chlorat reducirt, also 23 Proe. der zugesetzten Menge. In Versuch 90 (Temperatur und Versuchsdaner wie in Versuch 82) werden $20 \mathrm{ccm}$ Blut und $10 \mathrm{ccm} 2,5$ proc. Kaliumchloratlösung ( 0,83 proc. Chloratiösung) zusammengebracht und $149 \mathrm{mg}$ Chlorat reducirt, also 59 Proc. der zugesetzten Menge. Endlich liefern Versuch 88 und 97 fast ähnliche Ergebnisse. Die Versuchsdauer ist auch hier wieder dieselbe (24 Stunden), die Temperatur bietet wenig Unterschied, 22 und $25{ }^{\circ} \mathrm{C}$. Dennoch werden in Versuch 97, wobei $300 \mathrm{ccm}$ Blut in Anwendung kamen, 64 Proc. des zugesetzten Cblorats reducirt (der Procentgehalt an Chlorat der Fliissigkeit war 0,161 Proc.), in Versuch 88 dagegen mit fast ähnlichem Chloratgehalt der Flüssigkeit $(0,166$ Proc.), in welchem nur $20 \mathrm{ccm}$ Blut an. gewandt wurden, nur 22 Proc. der zugesetzten Menge.

Dennoch passt nicht zu dieser Vorstellung, dass grosse Quantitäten Blut nicht im Stande sind, selbst sehr geringe Mengen Chlorat innerbalb kurzer Zeit vollkommen zu reduciren. Erst nach längerer Zeit erfolgt die vollständige Reduction, wenn «. B. $100 \mathrm{ccm}$ Blat mit $5 \mathrm{mg} \mathrm{Ka-Chlorat} \mathrm{zusammengebracht} \mathrm{werden.} \mathrm{Es} \mathrm{meint} \mathrm{deshalb} \mathrm{auch}$ v. Mering, dass bei gleicher Zeitdauer und Temperatur die Reduction in erster Linie von der absoluten Menge des vorhandenen Chlorats abhängig ist oder, wie er sich auch noch auf andere Weise ausdrïckt: Die Mengen von Kaliumchlorat, welche in einzelnen Fällen reducirt werden, hängen ab und sind bestimmt durch den gleichzeitig vorhandenen Ueberschluss von unzersetzt bleibendem Sal7. Dies auf- 
fallende Verhalten des chlorsauren Kali im Blat weist nach seiner Meinung also auf eine Art chemischer Processe bin, welche man als Massenwirkungen zu betrachten gewöhnt ist.

Es scheint mir dieser Schluss nicht ganz gerechtfertigt, da, wenn man die einzelnen diesbezüglichen Versuche durchgeht, öfters bei einer geringen Menge zugesetztem Kaliumchlorat relativ mehr redncirt wird, wie bei einer grösseren Menge.

So kommen in Versuch $99100 \mathrm{mg} \mathrm{NaClO}_{3}$ in Anwendung, die Temperatur beträgt $22^{\circ} \mathrm{C}$., die Versuchsdauer etwas mehr wie 24 Stunden; die reducirte Menge ist gleich $59 \mathrm{mg}$. Es sind also 59 Proc. der zugesetzten Menge reducirt worden. In Versuch 82 dagegen kommt eine 5 mal grössere Menge, $500 \mathrm{mg}$, in Anwendung, die Temperatur beträgt $25^{\circ} \mathrm{C}$, die Versuehsdaner 40 Stunden, die redueirte Menge nur $115 \mathrm{mg}$, also 23 Proc. Andererseits ist bei gleichen Mengen anwesenden Kaliumchlorats die Reduction durchaus nicht gleich, auch wenn die Temperatur und die Zeitdauer fast übereinstimmen. Nehmen wir z. B. Versuch 87 und 91. In beiden wird dieselbe Menge Chlorat zugesetzt: $500 \mathrm{mg}$. Versuch 87 dauert 240 Stunden bei einer Temperatur von $15^{\circ} \mathrm{C}$., Versuch 91504 Stunden bei einer Temperatur von $25^{\circ} \mathrm{C}$. Man sollte also erwarten, dass die Reduction in Versuch 91 viel stärker wäre wie in Versuch 87, gerade das Umgekehrte ist der Fall: die Reduction beträgt in Versuch $87377 \mathrm{mg}$ (also 75,4 Proc.), in Versuch 91 dagegen $273 \mathrm{mg}$ (also 54,6 Proc.).

Die Unterschiede finden nun ihre Erklärung in den verschiedenen Mengen Blut, mit welchen experimentirt wird, und wie schon früher auseinandergesetzt ist, so nimmt ceteris paribus die Grösse der Reduction mit der Menge des Blutes zu (Versuch $99100 \mathrm{~g}$, Versuch $8210 \mathrm{~g}$, Versuch $8750 \mathrm{~g}$, Versuch $9120 \mathrm{~g}$ Blut).

leh glaube daher v. Mering in seinen Schlussfolgerungen nicht beitreten zu können. Nur durch eine Umrechnung der erhaltenen Resultate auf $100 \mathrm{ccm}$ Blut ist er zu der Annahme einer sogenannten Massenwirkung gekommen und diese Umrechnung scheint mir in den gegebenen Fällen, wo es darum zu thun ist, den Antheil des Blutes und des Chlorats an den Erscheinungen festzustellen, nicht erlaubt. Auch wird durch keinen einzigen Versuch seine Behauptung gestiitzt, dass, wenn $100 \mathrm{ccm}$ Blut in 24 Stunden z. B. ein Zehntel des zugesetzten Salzes reoueiren, dieselbe Wirkung nicht erzielt wird, wenn man derselben Quantität Blut unter sonst ganz gleichen Verhältnissen gerade die Menge überhaupt zusetzt, welche im ersten Falle reducirt wurde.

Wie dem nun auch sei, man muss zugeben, dass in keinem Fall der Schliissel aller dieser Erscheinungen in einfachen chemischen Affinitätsverhältnissen zu suchen ist, und wenn ich unumwunden meine Ansicht aussprechen soll, so weisen meines Erachtens alle Wider- 
sprïche darauf hin, dass es sich hier um complicirte Processe handelt, welche sich im absterbenden Blut abspielen. Diese Processe sind Fermentations - oder Fäulnissvorgänge, deren Intensität in erster Instanz durch Temperatur und Zeitdauer bestimmt wird und wobei einerseits die Blutbestandtheile langsam zerfallen, andererseits das chlorsaure Salz zersetzt wird. Ob nun das wirksame Ferment, wie äusserst wahrscheinlich ist, vom Blut selbst geliefert wird oder von aussen in die Blutflüssigkeit gebracht und da einen üppigen Boden zu seiner Entwicklung und seiner Wirksamkeit findet, können wir für den Augenblick ganz dahingestellt sein lassen. Sobald der Fermentationsvorgang im Gange ist und freie Chlorsäure als solche oder Sauerstoff aus dem zugesetzten Chlorat abgespalten wird, so wird auch das Hämoglobin in makroskopisch und spectroskopisch sichtbarer Weise angegriffen, es bildet sich Methämoglobin, Hämatin. Ist die Menge des anwesenden Chlorats gegenüber derjenigen des Blutes sehr gering, so wird kein oder kein erkennbares Methämoglobin erzeugt, das Chlorat erleidet aber dennoch eine Reduction. Sind die Chloratmengen relativ grosse und ist $z u$ gleicher Zeit viel Blut anwesend, so wird sowohl viel Methämoglobin gebildet als viel Chlorat reducirt werden. Bei der Bildung einer grossen Menge Methämoglobins erleidet aber das Blut noch eine andere, nicht genauer bekannte Veränderung, wobei es in eine gallert - oder kautschukartige Masse umgewandelt wird, und welche einer weiteren Zerlegung Schranken zu setzen scheint, da solche Massen während sehr langer Zeit sich vollkommen unverändert erhalten.

Ich weiss nun sebr wohl, dass auch bei dieser Vorstellung einzelne Details in den mitgetheilten Erscheinungen noch ganz unerklärt bleiben, aber dies kann für uns kein Wunder nehmen, da ja der Fermentationsvorgang selbst uns nur unvollkommen bekannt ist. Dass es sich hier aber nur um einen Vorgang im absterbenden Blut handelt, wird für mich noch besonders durch die Thatsache bewiesen, welche die Untersuchungen v. Mering's über den begünstigenden Einfluss des Kohlensäurereichthums und der sauren Reaction des Blutes an den Tag gebracht haben. Auch im absterbenden Blute nimmt die Kohlensäure zu, werden Säuren gebildet; andererseits gibt es kein besseres Mittel, um das Absterben des Blutes einige Zeit hintanzubalten, wie Sauerstoff und alkalische Reaction, und beide Umstände sind, wie wir wissen, vollkommen geeignet, um das Eintreten der Methämoglobinbildung im chlorathaltigen Blut zu verlangsamen.

Es besteht nach meinem Dafürhalten höchst wahrscheinlich kein 
anderer Unterschied zwischen der Reduction der Chlorate im faulenden Harn und anderen faulenden Flussigkeiten und derjenigen im absterbenden Blute, als dass in der letzten Flïssigkeit der Fermentationsvorgang besonders schnell eintritt, und dass in derselben eine Substanz, das Hämoglobin, anwesend ist, welche, wenn sie von dem in Freiheit gesetzten Sauerstoff angegriffen wird, sogleich solche auffallende Veränderungen zeigt, dass sie von Jedem ohne Mühe erkannt werden können.

\section{Ueber Methämoglobinbildung im Blute des lebenden Organismus unter dem Einflusse chlorsaurer Salze.}

Seit dem Erscheinen der Arbeiten Jäderholm's und Marchand's, seitdem man weiss, dass bei der Anwesenheit von Chloraten aus dem Hämoglobin des Blutes Methämoglobin gebildet wird, hat man fast ohne Weiteres die toxischen Eigenschaften der chlorsallren Salze der dadurch bewirkten Blutdissolution zugeschrieben. Weil man das Blut ausserhalb des Körpers unter dem Einflusse der Chlorate sich ziemlich schnell zersetzen sah, weil man in dem Leichenblut der mit Chloraten vergifteten Individuen stets Methämoglobin vorfand, lag es auf der Hand, anzunehmen, dass auch im Iebenden Blut eine Methämoglobinbildung unter dem Einflusse der chlorsauren Salze stattfinden muss. In dieser Annahme wurde man verstärkt durch das Vorkommen von Hämoglobin und Methämoglobin im Harn während des Lebens, durch auffällige Veränderungen in den Nieren nach dem Tode und durch den Umstand, dass es einige Male gelang, in dem vor dem Tode untersuchten Blute eine eigenthümliche Veränderung: der rothen Blutkôrperchen und Methämoglobin nachzuweisen. Ein strenger Beweis aber, dass im lebenden Organismus dieselben Veränderungen wie ausserhalb desselben stattfinden, wie auch der Beweis, dass anch das lebende, in den Gefässen circulirende Blut unter dem Einflusse der Chlorate zersetzt wird, ist nicht geführt worden. Dieses Beweises bedürfen wir um so mehr, als wir wissen, dass, wäh. rend ausserhalb des Organismus Methämoglobinbildung und Reduction der Chlorate mit einander zusammengehen, das Bestehen einer Reduction des in den lebenden Organismus dureh innerliche Verabreichung oder subcutane Einspritzung eingefiuhrten Natrium- und Kaliumchlorats aus den diesbezüglichen Versuchen nicht erschlossen werden kann. Sowohl grössere als kleinere Mengen Natrium - und Kaliumchlorat passiren den lebenden Organismus und deshalb auch das Blut unverändert, und werden wieder völlig durch den Urin ausgeschieden -, so war ja der Schluss, zu welchem alle Untersuchungen von 
denjenigen Is a mbert's an bis zu denjenigen $v$, Mering's mit Bestimmtheit drängten. Wenn es nun auch voreilig wäre, aus Alledem auf eine Unantastbarkeit des lebenden Blutes durch chlorsaure Salze zu schliessen, so sieht man andererseits leicht ein, dass alle Versuche mit noch so frischem Blute, ausserhalb des Organismus angestellt, vollkommen ausser Stande sind, das Bestehen einer Methämoglobinbildung im lebenden Blut zu beweisen. Das Blut ist ja keine eigentliche chemische Flüssigkeit in des Wortes wahrer Bedeutung, wie der Harn; es ist, wie dies vor Jahren schon ganz ausgezeichnet ausgedruickt worden ist, ein flüssiges Gewebe. Dieses Gewebe stirbt, sobald es nicht mehr mit der lebenden Gefässwand in Berührung ist, ausserordentlich schnell $\mathbf{a b}$, und die Coagulation des Blutes ist die erste Erscheinung seines Absterbens. Versuche mit defibrinirtem Blut können uns also nie völligen Aufschluss geben über die Verhältnisse, welche im circulirenden lebenden Blute selbst obwalten. Wollen wir Aufschlüsse über die Schicksale der Chlorate im lebenden Blute und umgekehrt uiber die Zersetzbarkeit des lebenden Blutes durch chlorsaure Salze erhalten, so miissen wir uns zum lebenden Blute selbst wenden. Am ersten scheint es da geboten, die Erfolge zu studiren, welche die directe Einfuhr chlorsaurer Salze in das lebende Blut mit sich bringt.

Literaturangaben iiber diesen Gegenstand fehlen nicht. O'Sh agnessij injicirte einem Hunde einmal $3 \mathrm{~g}$ Kaliumchlorat, einem anderen Thiere $2 \mathrm{~g}$ in die Vena cervicalis ohne jeden nachtheiligen Erfolg. Laborde injicirte bei derselben Thierart grössere Mengen, selbst bis $10 \mathrm{~g}$ auf einmal, wieder ohne allen Nachtheil. Tacke sah nach intravenöser Injection von $2 \mathrm{~g}$ Natriumchlorat bei einem kleinen Kaninchen keine nennenswerthen Erscheinungen eintreten. Diese letzte Mittheilung ist um so merkwürdiger, als ja zur Zeit der Untersuchungen Tacke's die Methämoglobinbildung unter dem Einflusse chlorsaurer Salze schon bekannt war, und er gewiss nicht ver* säumt haben würde, dieselbe zu erwähnen, wenn er entweder aus dem Verhalten des Harns oder aus demjenigen des Blutes auf das Vorhandensein des Methämoglobins im lebenden Organismus hätte schliessen können. Auch die Arbeit Marchand's bringt in dieser Beziehung nur Enttäuschungen, weil alle seine Versuche mit directer intravenöser Injection des Chlorats misslangen. Für die Richtigkeit seiner Behauptung, dass auch im lebenden Blut sich Methämoglobin bildet, scheint nur ein Versuch zu sprechen, welcher schon früher von Isambert angestellt war und von ihm wiederholt wúrde, in welchem $10 \mathrm{~g}$ Natriumchlorat in die Bauchhöhle eines $8,3 \mathrm{~kg}$ schweren 
Hundes injieirt wurden. Eine kurz vor dem Tode entnommene Blutprobe zeigte hier einen dunklen Streifen im Roth, während in der Leiche das Blut und alle blutreichen Theile rauchschwarz aussahen. Besieht man jedoch dieses Resultat genaner, so beweist das Auffinden des Methämoglobins in einer Blutprobe kurz vor dem Tode eigentlich nicht viel. Erstens nicht, weil wir wissen, dass der Tod ja nie mit einem Mal eintritt und alle Gewebe zu gleicher Zeit trifft, so dass also kurz vor dem Tode - bei mehr und mehr abnehmender Respiration und mehr und mehr zunehmender Herzlähmung - das Blut eigentlich nicht mehr als recht lebend betrachtet werden kann. Zweitens nicht, weil es vollkommen unmöglich ist, lebendes Blut dem Körper zu entnehmen, da es ja in demselben Augenblick des Entnehmens abstirbt. Nur innerhalb der lebenden Gefässwände lässt sich das lebende Blut studiren, und wenn wir itber die Blutzersetzung im lebenden Körper durch Chlorate Aufklärung verlangen, so müssen wir uns nicht mit der Untersuchung kurz vor dem Tode entnommener Blutproben begnügen, wir müssen nachforschen, ob sich die Blutzersetzung nicht auf andere Weise unzweidentiger kundgibt. Und da lässt sich sehr leicht der Nachweis bringen, dass das in der Blutbahn circulirende Methämoglobin, wenn nur die Menge desselben nicht zu gering ist, in den Harn übergeht und eine Methämoglobinurie veranlasst, welche gewöhnlich einige Zeit andauert und deren Erkennung keine Schwierigkeit macht. In dem soeben erwähnten Versuch Marchand's ist nun von Methämoglobinurie ebensowenig. die Rede, wie in dem vollkommen gleichen Versuch Isambert's. Es steht uns nun noch ein anderer Versuch zur Verfïgung, und zwar ein Versuch v. Mering's ${ }^{1}$ ), weleher absichtlich angestellt wurde, um zu, zeigen, dass chlorsaures Salz auch im Blute während des. Lebens reducirt wird und dass sich dabei Methämoglobin bildet. Es wurden einem $10 \mathrm{~kg}$ schweren Hunde, dessen beide Ureteren unterbunden waren, $5 \mathrm{~g}$ Natriumchlorat in $50 \mathrm{ccm}$ Wasser in die Vena jugularis injicirt. Nach 5 Stunden war das Thier noch gesund, es zeigte keine Athembeschwerden; von einer Vergiftung oder von Dyspnoe, welche, wenn sich Methämoglobin in etwas bedeutender Menge gebildet hatte, nothwendig hätte eintreten mïssen, war also keine Rede. Nun wurde das Thier durch Verbluten getödtet und es zeigte sofort das entnommene Blut die charakteristische Verfärbung. Dennoch war der im Nierenbecken befindliche Urin völlig klar und frei von Eiweiss. Legt man diese beiden Resultate neben einander, so fällt 
der Widerspruch sogleich auf. Wenn wirklich Methämoglobin im lebenden, circulirenden Blut gebildet war, weshalb ging es dann nicht in den Urin ïber? Man könnte einwenden, dass die Menge des gebildeten Methämoglobins so gross war, dass dadurch Verstopfung der Nierengefässe auftrat, aber dann hätte auch kein Harn im Nierenbecken abgesondert sein können. Der klare eiweissfreie Urin beweist unseres Erachtens, dass während des Lebens im circulirenden Blute keine Zersetzung stattgefunden hatte und dass die Methämoglobinbildung nur in den Augenblicken, in welchen das Blut aus der Ader floss, also nur in dem der Circulation entzogenen Blut, aber hier dann auch sofort, vor sich ging.

Aus Alledem erhellt zur Genüge, dass die zahlreichen hier bestehenden Widersprïche nur durch eine neue Versuchsreihe, in welcher grössere oder kleinere Dosen chlorsaurer Salze direct intravenös bei Thieren eingeführt werden, zur Lösung gebracht werden können. Ein solche Versuchsreihe ist nun theils von Herrn v. Gorkom, theils von mir selbst in meinem Laboratorium angestellt. Absichtlich wurden zu diesen Versuchen vorzugsweise Kaninchen verwendet, da bei dieser Thiergattung schon relativ sehr kleine Mengen Hämoglobins und Methämoglobins ( $25 \mathrm{mg}$ auf $1 \mathrm{~kg}$ Thier) in den Harn übergehen. Es zeigte sich nun, dass die intravenöse Injection mässiger Dosen - 1"g Natriumchlorat auf $1 \mathrm{~kg}$ Thier - durchaus ohne jede Vergiftungserscheinungen verläuft. Schon 5-10 Minuten nach der Einspritzung ist das Chlorat deutlich im Harn nachweisbar und kann darin gewöhnlich selbst 2 mal 24 Stunden nach der Operation noch ohne Mithe aufgefunden werden. Der Harn enthält nie Methämoglobin oder irgend ein anderes Zersetzungsproduct des Blutfarbstoffes; nur wird Eiweiss darin regelmässig angetroffen, zwar in kleinen Mengen, aber doch vollkommen unverkennbar. Die Albuminurie dauert $1-3$ Tage und zeigt sich sehr bald nach der Injection, sobald die Ausscheidung des Chlorats anfängt. Zu gleicher Zeit enthält der Harn, wenigstens während der ersten Tage, Zucker. Besonders auffallend ist noch die ausserordentliche Steigerung der Harnsecretion während und kurze Zeit nach der Injection, so dass in diesem Zeitranme ein klarer, wasserheller, durchaus ungefärbter Harn aus dem in die Blase eingefithrten Katheter fast fortwährend abträufelt. 1) Es war also in diesen Versuchen die Einfuhr einer durchaus nicht unerheblichen Menge des Chlorats setzt man nämlich die Blutmenge des Kaninchens auf $1 / 15$ des Körper-

1) Auf die diuretische Wirkung der chlorsauren Salze hoffe ich bei einer. späteren Gelegenheit noch zurückzukommen. 
gewichts, so kamn, auch wenn man der fortwäbrenden Ausscheidung des eingefuhrten Salzes Rechnung trägt, der Chloratgehalt des Blutes bis auf 1 Proc. betragen haben - vollkommen ausser Stande, eine irgend erhebliche Methämoglobinbildung im lebenden Organismus hervorzurufen. Und dennoch zeigte die Untersuchung der gleich nach der Injection aus der A. carotis und der Vena cruralis entnommenen Blutproben, dass in dem sich selbst überlassenen und absterbenden Blut sich allmählich vollkommen deutlich Methämoglobin bildete.

Auch hier wurde diese Bildung durch eine Temperatur von 37 bis $38^{\circ} \mathrm{C}$. gefördert - denn die im Brütofen aufgestellte Blutprobe zeigte schon 3/4 Stunden nach der Entnehmung das charakteristische Aussehen und den charakteristischen Methämoglobinstreifen. Aber anch hier ergab sich ein grösserer Kohlensäuregehalt des Blutes als ein förderndes, ein grösserer Sauerstoffgebalt dagegen als ein die Methämoglobinbilduug verzögerndes Moment, denn es branchte selbst im Brütofen das arterielle Blut eine viel längere Zeit zur Verfärbung als das venöse Blut, und in dem auf Zimmertemperatur sich selbst iiberlassenen arteriellen Blut war nach 24 Stunden die Zersetzung nur bis auf die Bildung von Methämoglobin, in dem unter denselben Umständen sich befindenden renösen Blut dagegen schon bis auf die Bildung von Hämatin fortgeschritten.

Die Deutung dieser Versuche unterliegt keiner Schwierigkeit. Sie zeigen, dass die Methämoglobinbildung im lebenden Organismus nach der directen Injection mässiger Mengen Natriumehlorats nicht nachweisbar ist, sich aber dennoch mit allen den ihreigenthümlichen Erscheinungen in dem Blute vollzieht, welches gleich nach der Injection dem Organismus entnommen wird. Man darf also ganz ruhig schliessen, dass, wenn das Thier kurz nach der Injection getödtet und die Leiche erst einige Stunden später zur Untersuchung gekommen wäre, sie ohne jeden Zweifel das charakteristische Aussehen eines durch Chlorat getödteten Thieres geboten und zur Annahme der Chlorateinfuhr als Todesursache und einer während des Lebens stattgefundenen Blntzersetzung Anlass gegeben haben wïrde. Beide Schlüsse wären aber unbedingt falsch gewesen, denn die eingeführte Chloratmenge hatte zu keiner irgend bedeutenden Störung der Gesundheit geführt und von einer Blutzersetzung während des Lebens war keine Spur vorhanden. Es stimmt also dieser Befund ganz vollkommen zu der schon unter II entwickelten Auffassung, dass die Methämoglobinbildung unter dem Einflusse chlorsaurer Salze nur als ein Zeichen des absterbenden Blutes, als eine Leichenerscheinung zu betrachten sei. Ein gutes Seitenstïck zu dom Resultat dieser Versuche bildet folgender Versuch, in welchem bei einem 
durch Aconitin vergifteten Thiere im Augenblick des Absterbens eine intravenöse Injection einer Chloratlösung gemacht wird und das charakteristische rauchschwarze Ansehen der geöffneten Leiche - welches anf Methämoglobinbildung berubt - sich innerhalb kürzester Zeit auf deutlichste Weise entwickelt.

\section{Versuch 1.}

24. Juli 1884. Kaninchen, $1350 \mathrm{~g}$.

$2 \mathrm{~h} .400 \mathrm{mg}$ Aconitin in den Magen.

$2 \mathrm{~h} 10 \mathrm{~m}$. Bedeutende Verlangsamung der Herzfrequenz und der Respiration.

$2 \mathrm{~h} 15 \mathrm{~m}$. Herz und Respiration stehen still; noch einige Krämpfe.

$2 \mathrm{~h} 21 \mathrm{~m}$. Injection von $26 \mathrm{ccm}$ einer 10 proc. Natriumchloratlösung. Das Thier ist vollkommen reactionslos. Es besteht noch Exophthalmus und Pupillenerweiterung.

$2 \mathrm{~h} 24 \mathrm{~m}$. Beendigung der Injection. Während der Injection führt das Herz noch einzelne Contractionen aus. Der Thorax und das $\mathrm{Ab}$ domen werden eröffnet und es werden noch 2 oder 4 Herzcontractionen in einer Minute constatirt.

$2 \mathrm{~h} 30 \mathrm{~m}$. Das aus dem rechten Vorhof mittelst einer Pravaz'schen Spritze entnommene Blut fängt schon an braunroth zi werden.

$2 \mathrm{~h} 34 \mathrm{~m}$. Spectroskopischer Nachweis des Methämoglobins in diesem Blate.

$2 \mathrm{~h} 40 \mathrm{~m}$. Ranchschwarzes Aussehen der Leber, Lungen, des Darmes. Die rauchschwarze Färbung ist am intensivsten in den an das Herz grenzenden Organen. In dem in der Blase enthaltenen Harn ist Natriumchlorat nicht mit Sicherheit nachzuweisen.

Auch hier war das Aussehen der Leiche so charakteristisch, dass jeder Unbefangene keinen Augenblick Bedenken getragen haben würde, eine durch das Chlorat verursachte Vergiftung und eine während des Lebens zu Stande gekommene Zersetzung des Blutes anzunehmen. Dennoch war hier nur von einer Leichenerscheinung und von nichts Anderem die Rede.

Wie steht es nun mit dem Einfluss grösserer toxischer und letaler Dosen? Man muss hier einen Unterschied machen zwischen Hunden und Kaninchen in dem Sinne, dass bei Hunden nie von Hämoglobinurie oder Methämogiobinurie die Rede ist, auch wenn so grosse Dosen in das Blut gebracht worden sind, dass deutliche Vergiftungserscheinungen oder der Tod eintreten. Nur Eiweiss wird in kleinen Mengen bisweilen vortibergehend im Harn angetroffen. Bei Kaninchen dagegen wird in mehreren Fällen, wenn solche grosse Dosen angewandt sind, Hämoglobin und Methämoglobin im Harn angetroffen, daneben Blutkörperchen, Cylinder und selbstverständlich Eiweiss. Hier wäre also zum ersten Male von einer Erscheinung die Rede, 
welche auf eine Blatzersetzung während des Lebens deaten könnte. Nur muss gegen das Bestehen einer Blutzersetzung in diesen Fällen geltend gemacht werden, dass erstens ungeachtet dieser Erscheinung oft bei mehreren dieser Thiere nach einigen Tagen Unwohlseins völlige Genesung eintritt, dass zweitens die Menge des im Harn erscheinenden Methämoglobins immer eine unbedeutende, und dass drittens eine Vermehrung dieser Menge in dem sich selbst überlassenen Harn nicht zu verkennen ist. Dazu kommt noch, dass in den letal verlaufenden Fällen die Methämoglobinurie ganz fehlen kann und dass sie in der Regel fehlt, wenn das Kaninchen nicht durch intravenöse Injection des Natriumchlorats, sondern durch innerliche Verabreichung dieses Salzes in sebr grossen Quantitäten innerhalb 1 oder 2 Stunden getödtet wurde. Man kann sich dann ohne Mühe überzeugen, dass der Harn ungefähr dieselben Veränderungen zeigt, wie bei der intravenösen Injection mässiger, nicht toxischer Dosen, also Eiweiss und Zucker enthält, aber nie eine Spur von Blutfarbstoff. Dies Alles wäre vollkommen unverständlich, wenn unter dem Einflusse des eingeführten Chlorats eine Blutzersetzung während des Lebens zu Stande käme und das dabei gebildete Methämoglobin zur Ausscheidung gelangte. Denn wie wäre es dann möglich, dass die Zeichen dieser Blutzersetzung sich eben nur in den relativ günstig verlaufenden Fällen offenbarten und in denjenigen ganz vermisst würden, in welchen, trotz unbehinderter und bis zu dem Lebensende fortwährender Nierensecretion, der tödtliche Ausgang nicht ausblieb? Der Vorgang, der in den erwähnten Fällen bisweilen zur Methämoglobinurie führt, scheint uns nun klar genug und hat mit einer während des Lebens bestehenden Bildung von Methämoglobin im Blute nichts zu schaffen. Die Niere des Kaninchens ist ein besonders reizbares Organ, viel reizbarer als diejenige des Hundes. Die ziemlich concentrirten Salzlösungen (6 bis 8 Proc.), welche in allen denjenigen Versuchen angewandt wurden, wobei nur die intravenöse Einverleibung mässig grosser Dosen ( $1 \mathrm{~g}$ anf 1 Kilo Körpergewicht) bezweckt wurde (für ein Thier von $2 \mathrm{~kg}$ waren dazu beispielsweise $33 \mathrm{ccm}$ einer 6 proc. oder $25 \mathrm{ccm}$ einer 8 proc. Lösung nothwendig), hatten schon eine deutliche Albuminurie zur Folge. Aber wo es sich um toxische und letale Effecte handelte, musste wenigstens die doppelte oder dreifache Menge in die Vene injicirt werden, und um die injicirte Flissigkeitsmenge nun nicht übermässig gross zu machen, wurden Concentrationen von 10 bis 16 Proc. angewandt. Diese verursachten gewiss eine noch viel stärkere Reizung der Nieren und führten zu Blutungen in denselben. 
Sobald aber der Harn zu gleicher Zeit eine grosse Menge des chlorsauren Salzes and Blut enthielt, konnte natürlich Methämoglobinbildung in diesem bluthaltigen Harn nicht ausbleiben. Da nun eine längere Zeit währende Ausscheidung einer concentrirten Salzlösung selbstverständlich einen intensiveren Reiz abgibt als eine solche, welche nur sehr kurze Zeit anhält, so ist es klar, dass eben in den Fällen, welche bald mit dem Tod endeten, die Hämaturie und die Methämoglobinurie fehlten und besonders dann beobachtet wurden, wenn die Thiere am Leben blieben und die Nieren während längerer Zeit gereizt wurden. Andererseits muss die Concentration der Salzlösung, welche die Nieren passirt, wenn das Salz im Magen einverleibt worden ist, immer viel niedriger ausfallen, als diejenige, welche urspriinglich angewandt worden war. Die Resorption vom Magen aus geht allmählich von Statten; es gelangt in das Blut eine weniger concentrirte Salzlösung, welche nur zur Albuminurie, nicht zur Hämaturie führt. Die Richtigkeit dieser Erklärung, durch welche alle Widersprüche, wie man sieht, gelöst werden, war sehr leicht experimentell festzustellen. Es kam nur darauf an, nachzuweisen, dass nach intravenöser Injection concentrirter Kochsalzlösungen bei Kaninchen sich ebenso constant Albuminurie resp. Hämaturie zeigte, wie nach der Injection gleich concentrirter Chloratlösungen. Dieser Nachweis gelang nun in allen Stücken vollkommen und es ergab sich kein einziger Unterschied zwischen der Einwirkung dieser zwei verschiedenen Salzlösungen auf die Eiweiss - und Blutabscheidung im Harn, wenn nur die Concentration beider eine gleiche war, selbstverständlich war aber von Methämoglobinbildung in dem ClNa-Harn keine Rede.

Wenn also selbst nach der Injection sehr grosser Mengen Natriumchlorats in das Blut das Bestehen einer Methämoglobinbildung im Blute selbst, also das Auftreten einer Blutzersetzung während des Lebens nicht erwiesen werden kann, so wird es wohl kein Wunder nehmen, dass es ebensowenig gelingt, dieselbe während des Lebens durch innerliche Darreichung oder subcutane Einspritzung dieser Verbindungen zu erzeugen. Speciell will ich dazu noch erwähnen, dass auch die Einspritzung in die Peritonealhöhle ebenso unzweideutige negative Resultate ergibt und dass von einer Methämoglobinurie nach diesem Eingriff nie die Rede ist. ${ }^{\text {) }}$

1) Ich kann hier nicht unerwähnt lassen, dass selbst eine ziemliche Menge durch Natriumchlorat erzengtes Methämoglobin in die Peritonealhöhle oder subcutan injicirt werden kann, ohne in den Harn überzutreten. Diese Versuche wurden so angestellt, dass entweder frisches defibrinirtes Rinderblut, welchem Na- 
Dass nun wirklich die Methämoglobinbildung in dem Blute der durch chlorsaure Salze getödteten Thiere als eine Leichenerscheinung aufzufassen sei, dass sie durchaus nicht von einer während des Lebens stattfindenden Blutzersetzung abhängig bezeichnet werden kann, dafür sprechen noch folgende Umstände. Die eigenthümliche Verfärbung des Blutes zeigt sich nie vor dem Ende des Lebens. Selbst wenn sehr grosse, absolut letale Mengen in das Blut injicirt werden, zeigt das Blut der Vene, in welche die Chloratlösung direct einfliesst, nur bei annäherndem Tode - also wenn das Thier ganz regungslos daliegt - die eigenthümliche Farbe. Man sieht dann das Blut durch die Venenwand mit einer rauchschwarzen Farbe durchschimmern. Präparirt man nun in diesem Augenblick eine andere Vene, z. B. die Vena eruralis, so sieht man noch keine Spur der eigenthümlichen Farbe, welche erst einige Zeit nach dem Tode eintritt. Es stellt sich also, auch wenn das Blut förmlich mit Chlorat überschwemmt wird, immer wieder das Absterben des Blutes als das die Methämoglobinbildung bedingende Moment heraus, denn dass ja in der geöffneten und unterbundenen Vene das Blut eher absterben muss als in der ungeöffneten, ist ohne Weiteres klar.

Wenn nun nicht so grosse Mengen angewandt waren, so zeigte sich die Verfärbung des Blutes in der präparirten Vene auch noch nicht im Moment des Absterbens, und auch die entnommene Blutprobe ergab sich bei sofortiger Untersuchung als methämoglobinfrei. Erst allmählich und in kürzerer oder längerer Zeit nach dem Tode, je nachdem mehr oder weniger Chlorat verwendet war, zeigte sich die eigenthümliche Farbe.

Aus allen den bis jetzt mitgetheilten Thatsachen wird Jeder leicht die Ueberzengung gewinnen, dass das Bestehen einer durch Chlorate vermittelten Blutzersetzung während des Lebens vollkommen

Chlorat in Substanz zugesetzt war, oder welches durch Zusatz von Na-Chlorat in Substanz und darauffolgende Erwärmung auf $37^{\circ}$ während 24 Stunden fast vollkommen in methämoglobinhaltiges Blut umgewandelt war, zur Anwendung kam. In allen Fällen war schon innerhalb sehr kurzer Zeit das Chlorat im Harn nachweisbar. Dennoch fehlte Methämoglobin vollständig, während wenigstens bei Kaninchen auch kein anderes Zersetzungsproduct des Blutfarbstoffes im Harn aufgefunden werden konnte und auch Gallenfarbstoff oder Urobilin absolut in demselben vermisst wurden. Dies Resultat stimmt zu den Ergebnissen Kunkel's, dass in die Gewebe abgelagerter Blutfarbstoff nie in den Harn übergeht (Virchow's Archiv. LXXIX. Bd. S. 455), und wenn es auch davon in Bezug auf das vollständige Fehlen von Urobilinurie unter diesen Umständen abweicht, so darf man nicht vergessen, dass Kaninchen sich in dieser Beziehung anders verhalten wie Hunde. 
problematisch und dass diese Blutzersetzung, wo sie nach dem Tode vorhanden ist, nur als eine Leichenerscheinung zu betrachten ist. Die Intensität dieser Leichenerseheinung hängt hauptsächlich von zwei Momenten $a b$, und zwar erstens von der im Augenblicke des Todes im Blute vorhandenen Chloratmenge und zweitens von der An- oder Abwesenheit einiger die Blutzersetzung resp. die Methämoglobinbildung fördernden Bedingungen (Kohlensäurereichthum des Blutes im Augenblicke des Todes, Temperatur nach dem Tode u. s. w.).

Damit wird nun die ganze jetzt herrsehende Lehre, welche die toxische Wirkung der chlorsauren Salze auf eine Blutzersetzung ztrückführt, hinfällig; damit wird aber zugleich der innere Widerspruch gelöst, welcher zwischen dieser Lehre und der Thatsache besteht, dass kein Forscher bis jetzt eine irgendwie in Betracht kommende Reduction der chlorsauren Salze im lebenden Organismus hat nachweisen können, ein Widerspruch, welcher besonders in der so verdienstvollen Monographie v. Mering's grell hervortritt. Damit verschwindet aber zweitens ein anderer Widerspruch, welcher sich zwischen der Annahme einer Blutzersetzung als Ursache des Todes bei Chloratvergiftung und einigen unserer Versuche ergeben hat, in welchen eine Blutzersetzung in der Leiche einiger dureh Chlorat getödteter Thiere gar nicht oder wenigstens nicht während unserer Beobachtung nachweişbar war. In aller Kürze mögen hier diese Versuche Erwähnung finden.

\section{Versuch 2.}

Kräftig gut genährtes Kaninchen von $2260 \mathrm{~g}$ Körpergewicht. Einfuhr in den Magen von $120 \mathrm{ccm}$ einer $5 \frac{1 / 2}{2}$ proc. Kaliumchloratlösung. Tod innerhalb 21/2 Stunden. Section 11/2 Stunden nach dem Tode. Obgleich die Blutgefässe des Magens braunroth-ranchschwarz aussehen, ist das Blut im Herzen absolut methämoglobinfrei; L e ber, Lunge n, Niere, Milz haben ihre normale Farbe. In dem sich selbst überlassenen und in einem D on né 'schen Lactoskop aufbewahrten Blut ist erst nach 24 Stunden eine schwache Andeutung des Methämoglobinstreifens anwesend, welche aber gleich nach dem Zusatz destillirten Wassers zu dem Blute deutlicher und intensiver wird. Nach 2 mal 24 Stunden ist das Methämoglobin in dieser Blutprobe recht deutlich erkennbar. Die der Leiche entnommenen und bei Zimmertemperatur (im Winter) sich selbst überlassenen Organe (Herz, Leber, Niere, Milz) zeigen auch nach 2 mal 24 Studen keine Spur der charakteristischen braunselhwarzen Farbe.

\section{Versuch 3.}

Kräftiges kleines Kaninchen von $1150 \mathrm{~g}$ Körpergewicht. Ureterenunterbindung (bei der Operation ziemlicher Blntverlust). Eine Stunde nachher Einspritzung von $3 \mathrm{~g} \mathrm{Na-Chlorat} \mathrm{in} \mathrm{den} \mathrm{Magen.} \mathrm{Tod} \mathrm{innerhalb}$ 
16 Stunden nach der Einspritzung. Bei der 19 Stunden nach der Einspritzung vorgenommenen Section wird nirgends die braunschwarze Farbe angetroffen und es ergibt sich das Blut als methämoglobinfrei. Die Leiche wird nicht anfbewahrt, ebensowenig das Blut.

Versuch 4 u. f.

In diesen Versuchen erhielten Kaninchen, welche schon während längerer oder kürzerer Zeit Na-Chlorat mit der Oesophagussonde erhalten hatten und welche darunter keine anderen Erscheinungen als verminderten Appetit und Emaciation zeigten, also nur heruntergekommen waren, auf einmal eine grössere Dosis, welche aber nie $6 \mathrm{~g}$ Na-Chlorat überstieg, also an und für sich selbst weder eine toxische noch letale Dosis. Bei dem darauf öfters erfolgenden Tod der Thiere wurde nie Methämoglobin im Blute angetroffen und zeigte die Leiche keine Spur der charakteristischen Färbung.

Nachdem wir also festgestellt haben, dass erstens eine Reduction der chlorsauren Salze im Organismus sich in keiner Versuchsreihe nachweisen liess (I), dass zweitens die Vorgänge der Blutzersetzung unter dem Einflusse chlorsaurer Salze ausserhalb des Organismus am besten als Fäulnissvorgänge aufgefasst werden (II), dass endlich drittens eine Methämoglobinbildung im lebenden Blute selbst bei der Einfuhr grösserer und sehr grosser Dosen der Chlorate nicht angenommen werden kann, kommen wir zu dem schon oben angegebenen, jetzt durch mehrere Argumente erhärteten Schluss, dass die toxische Wirkung derchlorsauren Salze unmöglich voneiner durch sie verursachten Zersetzung des circulirenden Blutes abhängig gemacht werden kann. Worin dann die Ursache dieser toxischen Wirkung gesucht werden muss, das wollen wir in Folgendem besprechen.

\section{Die Ursache der toxischen Wirkung der chlorsauren Salze.}

Unsere toxikologische Kenntniss iiber die chlorsauren Salze bezieht sich fast ausschliesslich auf die Wirkung des Kaliumehlorats. Wenn auch bei Thieren einzelne Versuche iiber die Wirkung des Natriumchlorats angestellt worden sind (Marchand, Tacke), so ist doch ihre Anzahl eine unbedeutende; von vorneherein muss man aber zugeben, dass zur Erforschung der giftigen Wirkung der chlorsauren Salze das Natriumchlorat sich viel besser wie das Kaliumchlorat eignet. Erstens, weil seine Löslichkeit eine viel grössere ist, so dass man selbst sehr concentrirte Lösungen (20-25 proc.) anwenden kann, während das Kali chloricum bekanntlich selbst aus 5 proc. Lösungen auf die Dauer auskrystallisirt; zweitens aber hauptsächlich, weil die den Kalisalzen 
innewohnende giftige Wirkung ganz gewiss auch dem Kali chloricum zukommt und also das Vergiftungsbild trübt. Es sind dann auch gewiss nur theoretische Deductionen gewesen, welche v. Mering zu der Aeusserung führten, „dass bei der giftigen Wirkung des chlorsauren Kali der Kaligehalt wohl kanm in Betracht kommt, . . . ." da nach den Angaben von Bunge $225 \mathrm{~g}$ Kalisalz für den Menschen zar Herbeiführung des Todes durch Herzlähmung erforderlich sind und die bis jetzt angewandten tödtlichen Gaben von chlorsaurem Kali stets weniger wie $25 \mathrm{~g}$ Kali enthalten haben, und ihn schliesslich daran den Ausspruch knüpfen liessen, „dass es wohl wenig Sinn habe, das chlorsaure Kali durch das chlorsaure Natron ersetzen zu wollen".1) Mit vollem Recht hob dagegen Leichtenstern vor nicht zu langer Zeit hervor, "dass bei der acuten Vergiftung durch Kali chloricum die durch das Kalisalz bedingte Herzlähmung die Hauptsache sei" ${ }^{2}{ }^{2}$ ) Wer aber in der Literatur die letalen Dosen der verschiedenen Kalisalze beim Mensehen nachschlägt und dabei aufgezeichnet findet, dass die kleinste Menge, welche den Tod eines Erwachsenen verursacht hat, für chlorsaures Kalium $30 \mathrm{~g}$, für Salpeter $25 \mathrm{~g}$, für Kaliumsulfat $37,5 \mathrm{~g}$ betragen hat $^{3}$ ), wird wohl kaum sich der Meinung v. Mering's anschliessen können. Ausserdem ist es ein Leichtes, sich bei Thieren, namentlich bei Kaninchen, von der relativ viel geringeren Giftigkeit des $\mathrm{Na}$ triumchlorats gegenüber derjenigen des Kaliumchlorats bei innerlicher Anwendung zu tiberzeugen, da nach unseren Untersuchungen die letale Dose des Na-Chlorats sich auf $8-12 \mathrm{~g}$ auf $1 \mathrm{~kg}$ Thier, diejenige des Ka-Chlorats sich auf $2-2 \frac{1}{2} \mathrm{~g}$ auf $1 \mathrm{~kg}$ Thier - also 4 - bis 6 mal geringer herausstellt. Schon hieraus hätte man ohne Weiteres entnehmen können, dass die bis jetzt geltende Lehre über die Ursache der toxischen Wirkung der chlorsauren Salze unrichtig sein müsse; wird doch die Chlorsäure, nach den eigenen Versuchen v. Mering's, welche ich vollkommen bestätigt fand, noch ein wenig leichter aus dem Na-Chlorat als aus dem Ka-Chlorat abgespalten! Es müsste also die Blutzersetzung unter dem Einflusse des Na-Chlorats noch ein wenig leichter und schneller als unter demjenigen des Kalisalzes zu Stande kommen und das Natriumsalz bätte sich also nicht nur als gleich giftig, sondern noch um etwas giftiger als das Kalisalz ergeben müssen. Die Erfahrung zeigt aber gerade das

1) v. Mering 1. c. S. 139.

2) Leichtenstern, Zur Kali chloricum-Vergiftung. Deutsche med. Wochenschrift 1884. Nr. 4 und 20. Husemann's Jahresbericht über 1884. S. 366.

3) Falck, Lehrbuch der prakt. Toxikologie 1880. S. 331. 
Umgekehrte und damit zugleich das Irrige der jetzt herrsehenden Anschauungen.

Zum Studium der giftigen Wirkung der chlorsauren Salze als solche kann also nur das chlorsaure Natron gebraucht werden, denn das Kali chloricum verleugnet bei toxikologischen Versuchen seinen Kalicharakter, wenn ich mich so ausdrïcken darf, keineswegs. Die sowohl von Herrn v. Gorkom wie von mir bei Frösehen, Kaninchen, Hunden mit $\mathrm{Na}$-Chlorat angestellten Versuche zeigen nun in der That, dass man mit diesem Salz sowohl toxische wie letale Effecte erzielen kann, nur sind dazu sehr grosse Dosen erforderlich.

Um bei Fröschen Vergiftungserscheinungen bei innerlicher Darreichung hervorzurufen, muss man den Mund aufsperren und die ganze Mundhöhle förmlich mit kleinen Krystallen von Natron chloricum ausfüllen oder bei der subcutanen Einspritzung 2 oder $3 \mathrm{ccm}$ einer 10 proc. Lösung einführen. Die Thiere zeigen dann folgende Erscheinungen: Die Reflexerregbarkeit, welche anfänglich ein wenig erhöht ist und sich durch sehr leicht auszulösendes Quaken äussern kann, nimmt nach einiger Zeit $\mathrm{ab}$, während zu gleicher Zeit das Thier mehr oder weniger paretisch wird, sich leicht anf den Ruicken legen lässt, ohne seine gewohnte Stellung wieder einzunehmen, bei Beruihrungen nicht mehr fortspringt u. s. w, Haupterscheinungen der Vergiftung bilden aber die kleinen musculären Zuckungen, welche sowohl bei subcutaner Einspritzung als bei innerlicher Darreichung am ersten an den Muskeln des Kopfes und der Mundhöhle, darauf constant an den Zehen der Vorderpfoten und an den kleinen Muskeln der vorderen Extremitäten, dann aber später auch an den Zehen nnd den kleinen Muskeln der hinteren Extremitäten auftreten, bei Berührung heftiger werden und besonders deutlich sind, wenn das Thier auf dem Rücken liegt. Bei der subcutanen Injection werden diese Zuckungen ansserdem sehr schnell an den Muskeln beobachtet, welche in der Umgebung der Stelle liegen, an welcher die subcutane Injection stattfand. Diese Muskelzuckungen, welche sich nur selten zu wirklichen: Krämpfen steigern, sind - soweit es nicht die der Injectionsstelle naheliegenden Muskeln betrifft - durch eine Reizung des Centralnervensystems bedingt; denn sie verschwinden, sobald Gehirn und Rückenmark vollkommen zerstört sinđ. Ueberlässt man die Thiere sich selbst, so sterben sie in der Regel innerhalb 24 Stunden, und wenn die Temperatur nicht zn niedrig ist, so zeigen die blutreichen Theile der Leiche die ejgenthümliche braunschwarze Fürbung in unverkennbarer Weise.

Ich will zugleich hinzusetzen, dass die geschilderten Erscheinungen, die allgemeinen musculären Zuckungen, die Parese, die Abnahme der Reflexe durchaus nichts Charakteristisches bieten. Sie kommen nicht nur dem Chlorat als solchem, sie kommen ebensogut dem Kochsalz in denselben Concentrationen zu. Sie beruben auf dem schon längst bekannten und nicht genügend gewïrdigten dele- 
tären Einflusse concentrirter Salzlösungen ${ }^{1}$ ), und nur in zwei Beziehungen weichen die mit concentrirten Kochsalzlösungen bei $\mathrm{Fr} \ddot{o}$ sch en erzielten Functionsstörungen von denjenigen ab, welche durch Na-Chloratlösungen derselben Stärke verursacht wurden: erstens darin, dass die Katarakt sich bei Kochsalzanwendung viel schneller und deutlicher offenbarte, und zweitens darin, dass die Kochsalzthiere öfters nicht $\mathrm{zu}$ Grunde gingen, während bei den Chloratthieren fast ohne Ausnahme der Tod erfolgte.

Was nun Hunde und Kaninchen anbetrifft, so darf man ebenso ohne jeden Zweifel constatiren, dass nur grosse und sehr grosse Mengen Natriumchlorat im Stande sind, Vergiftung und Tod hervorzurufen.

Im Vorhergehenden wurde schon darauf aufmerksam gemacht, dass selbst nach der Einfuhr von $1 \mathrm{~g}$ chlorsauren Natrons pro Kilo Körpergewicht in das Blut bei Kaninchen sich keine anderen toxischen Erscheinungen als eine leichte vorïbergehende Albuminurie (und Glykosurie) entwickelt. Bei der innerlichen Darreichung kann man tagtäglich noch viel grössere Quantitäten, wenn sie nur nicht auf einmal in zu concentrirten Lösungen angewandt werden, einführen. ${ }^{2}$ ) In dieser Beziehung stimmen auch unsere Versuche ganz zu den von Marchand und Tacke mitgetheilten Fällen, indem es z. B. dem Ersteren nicht gelang, bei einem Hund von $17 \mathrm{~kg}$ durch eine tägliche Gabe von $10 \mathrm{~g} \mathrm{Na}$-Chlorat während einer ganzen Woche irgend welche toxische Wirkung hervorzurufen. Bei der subcutanen Einspritzung konnten wir nur bei kleinen Hündchen toxische, nie aber letale Effecte erzielen und wohl deshalb nicht, weil auf diese Art und Weise nie genügend grosse Dosen den Thieren beigebracht werden können. Um diesem Uebelstand abzuhelfen, könnte man zwar zu sehr concentrirten Lösungen (25 Proc. und mehr) greifen, aber dieselben sind so schmerzhaft, dass man davon sogleich Abstand nehmen muss. Dazu kommt noch, dass (wenigstens bei erwachsenen Hunden) ein ziemlich heftiges Fieber immer der subcutanen Einspritzung selbst mässig concentrirter Lösungen (10 Proc.) folgt, wodurch selbstverständlich das Vergiftungsbild ganz getrübt wird.

Das Intoxicationsbild, welches Hunde und Kaninchen bei der intravenösen Injection des Na-Chlorats darbieten, wenn 2-21/2 g per Kilo Thier injicirt werden, hat alle Hauptziuge mit demjenigen gemein, welches auch bei Fröschen hervortritt.

1) Man vergl. u. A. Christison, On Poisons. 1845. p. 656 und Herrmann, Experimentelle Toxikologie. 1874. S.173.

2) Auch für Kali chloricum ist die relative Ungefährlichkeit ziemlich grosser Dosen durch die übereinstimmenden Untersuchungen Is a mbert's, See's, La borde's und v. Mering's festgestellt. Nar wenn die Dose eine übermässig grosse, oder in zu concentrirter Lösung angewandt wird, oder auch das Thier schon längere Zeit vorher das Salz erhielt und nun auf einmal beim leeren Magen wieder eine neue Dose bekommt, zeigen sich die toxischen Erscheinungen. 
In den Vordergrund treten die kleinen musculären Zuckungen, welche regelmässig an den Muskeln des Kopfes anfangen, dann die oberen und endlich die unteren Extremitäten treffen. Am Kopfe sind es hauptsächlich die Muskeln der Schnauze, die Bewegungsmuskeln des Auges, welche betroffen werden und wodurch sich besonders bei Kaninchen ein unregelmässiges Zittern der Barthaare und Nystagmus ergibt. Nur gegen das Ende des Lebens werden die musculären Zuckungen an den Extremitäten, welche beim Kaninchen besonders dann deutlich hervortreten, wenn man die Thiere an den Ohren fasst und frei in der Luft hängen lässt, welche ausserdem bei jeder Berührung, beim Beklopfen des Operationstisches intensiver werden und also auf vermehrte Reflexerregbarkeit deuten, zu wirklichen Convulsionen. Es entwickelt sich anch bald nach diesem Stadium der Erregung ein Stadium der Depression, in welchem die Thiere nicht mehr im Stande sind, sich aufrecht zu erhalten, so dass die Vorder - und Hinterbeine ausrutschen und gespreizt werden und das Thier endlich ganz regungslos auf die Seite füllt, während der Nystagmus fortbestehen bleibt. $\mathrm{Zu}$ diesem komatösen und paralytischen Zustande gesellt sich alsbald eine dentliche Dyspnoe - die Respiration wird verlangsamt und unregelmässig - mit mehr oder weniger scharf hervortretenden Störungen in der Intensität und der Frequenz der Herzcontractionen (bei Hunden wird während der Injection eine starke Zunahme der Frequenz, später eine grosse Unregelmässigkeit beobachtet), es zeigen sich alsbald mehrere heftige Convulsionen, welche sich über den ganzen Körper ausbreiten und wodurch ein einziges Mal der ganze Thierkörper vom Boden geschleudert wird und dann das Thier innerhalb 1 oder 2 Stunden, bisweilen auch noch früher, nach dem Anfang der Injection erliegt. Der in dieser Periode abgeschiedene Harn enthält beim Kaninchen regelmässig Eiweiss und Blut, anch wohl einzelne Cylinder, beim Hunde öfters ein wenig Eiweiss. Von einer Stockung der Harnsecretion ist keine Rede; im Gegentheil fliesst der Urin stetig aus dem in die Harnblase eingeführten Katheter $a b$ und enthält schon $5-10 \mathrm{Mi}-$ nuten nach dem Anfang der Injection deutliche Mengen Chlorat. Ist die Dosis keine letale gewesen, so werden nur die musculären Zuckungen und eine Vermehrung der Respirationsfrequenz, auch wohl der Pulsfrequenz, beobachtet, die Somnolenz, die Paralyse, die Dyspnoe, die Veränderung der Herzfrequenz fehlen oder sind wenig entwickelt; nach einiger Zeit verschwinden die Zuckungen und das Thier erholt sich vollkommen. Nur enthält beim Kaninchen der Harn noch einige Tage Eiweiss, Blut und Cylinder. Im Leichnam der durch intravenöse Injection gestorbenen Thiere findet man keine nennenswerthen Veränderungen, ausser einem nie fehlenden Oedem der Lungen; die Nieren sind höchstens etwas hyperämisch; Milz, Leber u. s. w. zeigen sich ganz normal. Von der allmählich nach dem Tode sich entwickelnden Blutzersetzung sehen wir hier ganz ab.

Die toxische und letale Wirkung des intravenös injicirten NaChlorats ist nun in allen Stücken derjenigen concentrirter Kochsalzlösungen ähnlich. Es ergibt sich weder in den Symptomen der Vergiftung noch in den Dosen irgend ein Untersehied zwischen Koch- 
salz und Natriumchlorat. Unter beiden Umständen ist es nicht die eingefuihrte Substanz als solche, welche die letalen und toxischen Effecte hervorruft, es ist vielmehr die concentrirte Salzlösung, welche höchstwahrscheinlich erst eine reizende, dann eine deprimirende Wirkung auf das Centralnervensystem ausübt, welche die Nieren afficirt und als die Ursache des Lungenödems betrachtet werden muss. Schon Falck ${ }^{1}$ ) hat vor vielen Jahren die meisten dieser Erscheinungen bei der Injection concentrirter Kochsalzlösungen in das Blut ganz naturgetreu beschrieben, und wenn ich nicht weiter auf den Zusammenhang der einzelnen Erscheinungen eingegangen bin, wenn ich nur constatirt habe, dass im Anfange der Vergiftung Blutdruck, Puls- und Respirationsfrequenz nur ganz unbedentende Störungen erleiden, so geschah dies, weil ich mir die Aufgabe gestellt hatte, die toxische Wirkung des Natriumchlorats zu untersuchen, nicht derjenigen concentrirter Salzlösungen auf den Grund zu gehen. Vielleicht. werde ich die Untersuchung dieser Verbältnisse später wieder anfnehmen; für unseren jetzigen Gegenstand genügt es, festgestellt zu haben, dass Natriumehlorat bei intravenöser Injection nicht mehr und nicht weniger giftig ist wie das gewöhnliche Kochsalz, dass es also im strengen Sinne des Wortes nicht als ein eigentliches Gift betrachtet werden kann, man müsste dann auch Kochsalz den Giften anreihen.

Ueber die toxische und letale Wirkung des innerlich dargereichten Natriumchlorats kann ich mich nach dem oben Gesagten kurz fassen. Auch hier stimmt die toxische und letale Dosis des NaChlorats in allen Hinsichten mit derjenigen des Kochsalzes überein, auch hier tritt nach der Darreichung des Na-Chlorats kein einziges Vergiftungssymptom auf, welches sich nicht vollkommen mit denselben Zügen bei der Darreichung einer Kochsalzlösung der gleichen Concentration wiederfindet.

Die letale Dosis beträgt hier für beide Substanzen 8-10 g pro Kilo Thier (wenigstens bei Kaninchen, da ich, um nicht zu viel Thiere ohne dringende Nothwendigkeit zu opfern, keine Hunde zu diesen Versuchen verwendete). Die ersten Erscheinungen bestehen hier in einer gewissen Mattigkeit und Apathie des Thieres, in einer bedeutenden Zunahme der Respirationsfrequenz mit Dyspnoe, in einer nicht stark hervortretenden Abnahme der Herzfrequenz, während erst später die musculären Zuckungen auftreten und ibberhaupt nicht so stark ausgedrückt sind, wie nach der intravenösen Injection. $1 / 2$ oder 1 Stunde nach der Darreichung: dieser grossen Mengen der concentrirten Salzlösung fällt das Thier mehr oder weniger paretisch auf die Seite; die Respiration wird mühsamer,

1) Virchow's Archiv. LVI. Bd. S. 318. 
die Pulsfrequenz herabgesetzt, es zeigen sich einzelne, bisweilen sehr heftige Convulsionen, welche sich über den ganzen Körper ansdehnen und das Thier stirbt dyspnoisch. Bisweilen, durchaus nicht constant, zeigen sich Diarrhöen und der während der Vergiftung abgesonderte Harn enthält, wie schon fruiher erwähnt, immer Eiweiss und Chlorat. Bei der kurz nach dem Tode vorgenommenen Section findet man nun anch wieder constant Lungenödem, sonst aber keine deutliche oder constante Veränderung irgend eines Organes, ausgenommen den Magen und den Anfang des Duodenums. Die Schleimhaut des Magens ist immer in hohem Grade angeätzt, zeigt besonders an der grossen Curvatur intensive und ausgedehnte Blutungen, welche sich bis in die Submucosa ausdehnen; mit grösster Leichtigkeit lässt sich ein grösserer oder geringerer Theil desselben, welcher sich wie ein Fetzen verhält, von seiner Unterlage abheben, während die Duodenalschleimhaut meistens sich mehr durch eine ganz eigenthümliche Blässe, wie durch Röthung charakterisirt, mit einem Wort, der Magen (und zum Theil auch das Duodenum) zeigt die der Gastritis toxica zukommenden Erscheinungen in ausgeprägtester Weise.

Auch hier wieder ruft Kochsalz - in derselben Menge und in derselben Concentration auf einmal verabreicht - vollkommen dasselbe Vergiftungsbild auch in Bezug auf die Anätzung des Magens hervor. Die Vergiftungserscheinungen durch innerliche Darreichung beider Salzlösungen werden am besten so aufgefasst, dass die zum grössten Theil von der Gastritis toxica und den durch die heftige Reizung des Magens bedingten Reflexen auf Respirations- und Herzcentren abhängig gemacht werden, während sie zum Theil auch durch den Uebergang der Salzlösung in das Blut hervorgerufen sein mögen, welche dann an erster Stelle für die Nephritis und weiter auch vielleicht für die musculären Zuckungen verantwortlich gemacht werden miïssen. Kommen die Thiere mit dem Leben davon und ist die Menge und die Concentration der Salzlösung so getroffen, dass nur toxische, keine letalen Effecte eintreten, so legen sich die stürmischen Erscheinungen ziemlich bald und es bleibt nur während 3 bis 4 Tagen eine Albuminurie bestehen, bei welcher meistens zu gleicher Zeit etwas Blut und Cylinder in dem Harn vorkommen.

Es seien hier noch zwei für die Theorie dieser acuten Salzwirkung nicht uninteressante Thatsachen erwähnt. Die erste ist die, dass es für den letalen Effect des innerlich angewendeten Salzes keinen Unterschied macht, ob man eine und dieselbe Salzdosis das eine Mal in starken, das andere $\mathrm{Mal}$ in geringeren Concentrationen verabreicht. Obgleich man das Gegentheil erwartet haben sollte, so muss man doch bedenken, dass die letale Dosis eine sehr grosse ist und dass z. B. bei der Anwendung einer 25 proc. Lösung für ein Kaninchen von $2 \mathrm{~kg}$ zu diesem Zwecke wenigstens 85 -90 ccm dieser Lösung gebraucht werden. Will man nun dieselbe Dosis in geringerer Concentration, z. B. in einer 10 proc. Lösung geben, 
so braucht man für ein Thier von gleichem Körpergewicht eine $21 / 2$ mal grössere Flüssigkeitsmenge, also $210-220 \mathrm{ccm}$. Ob nun diese ungebeuer grosse Fluissigkeitsmenge, welche der Kaninchenmagen selbst gewöhnlich nicht auf einmal fassen kann, ungeachtet der relativ viel geringeren Concentration, denuoch durch ihre Masseneinwirkung die Schleimhant reizt und anätzt, oder ob eine ziemlich schnelle Resorption des Wassers der Salzlösung vor sich geht, so dass in dem Magen eine stärkere concentrirte Salzlösung zurückbleibt, wollen wir dahingestellt sein lassen, da wir vor der Hand nur auf die Thatsache als solche hinweisen wollen. Die zweite Thatsache ist die, dass die durch das Einbringen einer stark concentrirten Salzlösung vergifteten Thiere nicht am Leben erhalten werden konnten, auch wenn gleich nach dem Ausbruch der ersten musculären Zuckungen ziemlich grosse Mengen einer 11/2 proc. Kochsalzlösung in das Blut injicirt wurden, um anf diese Weise der schnellen Wasserverarmung der Gewebe entgegen zu treten.

Dass es nun auch eine chronische Salzwirkung geben kann, bei welcher die fortgesetzte Reizung des Magens durch relativ concentrirte Salzlösungen Diarrhöen und allgemeine Abschwächnng herbeithiht und die Thiere schliesslich zu Grunde richtet, wenn nur die Verabreichung lange genug fortgesetzt wird, oder auf einmal, nach mehreren kleinen, ganz unschuldigen Dosen, eine grössere, an und für sich selbst weder letale noch toxische Dosis gegeben wird, erhellt aus einigen von uns in dieser Richtung angestellten Versuchen. ${ }^{1}$ ) Ich will darauf vorläufig nicht weiter eingehen, möchte aber das Factum nicht unerwähnt lassen, um anzudeuten, dass eine chronische Vergiftung durch chlorsaures Kali nicht von vorneherein undenkbar ist.

Nach allen diesen Versuchen ist also der Schluss vollkommen gerechtfertigt, dass auch bei der innerlichen Darreichung sich das Natriumchlorat nicht mehr und nicht weniger giftig ergibt als das gewöhnliche Kochsalz.

Wenn alle die bis jetzt gezogenen Schlüsse richtig sind, wenn wirklich die Chlorsäure in dem Na-Chlorat keine selbständige Wirkung auf den lebenden Organismus ausübt, wenn chlorsaures Natrium und Chlornatrium sich in ihrem Verhalten zum lebenden thierischen Organismus als vollkommen identisch ergeben, so muss auch das chlorsaure Kali in allen seinen giftigen Wirkungen vollkommen mit dem Chlorkalium übereinstimmen. Für Diejenigen, welche noch Bedenken tragen möehten, ans der Gleichheit der bei

1) So starb in den Versuchen Dr. Kimmyser's ein Kaninchen, uachdem es öfters schon Na.Chlorat in kleinen Dosen genommen hatte, als ihm $6 \mathrm{~g}$ dieses Salzes - eine sonst absolut unschädliche Dosis - in ziemlich concentrirter Lösung auf einmal gegeben wurden. 
dem Menschen ohne jede Voreingenommenheit festgestellten letalen Dosen des Kaliumchlorats, - Nitrats und - Sulfats (siehe oben) diesen Schluss abzuleiten, und vielleicht noch geneigt wären, für eine eigene toxische Wirkung des chlorsauren Kaliums in die Schranken zu treten, ist nun eine derartige Versuchsreihe, bei welcher man die Identität der giftigen Wirkung dieser beiden Salze prüft, besonders lehrreich. Wählt man nämlich 2 Thiere (Kaninchen) von fast gleichem Körpergewicht, gibt man dem einen innerlich Kaliumchlorat in einer letalen Dose und von einer bestimmten Concentration, und dem anderen Chlorkalium in derselben Dose und derselben Concentration, so wird das letzte Thier noch schneller getödtet wie das erstere und die bei beiden Thieren ganz ähnlichen Vergiftungserscheinungen (schwache musculäre Zuckungen, Abnahme der Herzfrequenz, Parese, Dyspnoe, Albuminurie, Convulsionen, Gastritis toxica) sind bei diesem noch intensiver wie bei jenem. Daraus folgt mit Gewissheit, dass, abgesehen von der Salzwirkung, alles sich hier um die Kaliwirkung dreht, und da in dem Chlorkalium seiner elementaren Zusammenstellung nach mehr Kalium enthalten ist wie in einer gleichen Menge Kaliumchlorat, so stimmt der Erfolg ganz mit der von uns gemachten Voraussetzung, dass dem chlorsauren Kali keine andere selbständige Wirkung auf den Organismus zugeschrieben werden kann, als die, welche auch allen anderen Salzen und insbesondereallen Kalisalzen als solchen zakommt.

Ich darf schliesslich nicht unterlassen, den Beweis zu liefern, dass die von mir gegebene Darstellung der toxischen Wirkung des chlorsauren Kali und des chlorsauren Natrons ganz zu dem charakteristischen Bild der Kalium-(und Natrium-)Chloratvergiftung passt, wie dies z. B. von v. Mering in seiner ausführlichen Monographie entworfen ist. Es wird sich dabei klar herausstellen, dass zwischen den Beobachtungen am Menschen und der aus den Experimenten an Thieren von mir abgeleiteten Erklärung kein einziger Widerspruch besteht, und dass die von mir vertheidigte Vorstellung in mehr wie einem Punkte ebenso gut, ja vielleicht besser zu den Thatsachen stimmt, wie die jetzt fast allgemein zur Erklärung der Vergiftungserscheinungen angenommene Blutzersetzung.

Am besten werde ich dabei so verfahren, dass ich dem vorr v. Mering entworfenen Bilde auf dem Fusse folge und seine eigenen Worte wiedergebe, soweit sie auf den Thathestand sich beziehen.

Wir lesen also bei v. Mering ${ }^{1}$ ):

1) 1. c. S. 134 . 
„Man muss eine peracute und eine minder rasch verlaufende Vergiftung unterscheiden.

Bei den sehr rasch verlaufenden Fällen erfolgt der Tod in wenigen Stunden ....... Symptomatisch beobachten wir hartnäckiges Erbrechen, profuse Diarrhoe, tiefe Cyanose, Herzsehwäche. Der Leichenbefund ergibt chocoladenbraune Verfärbung des Blutes, während im Uebrigen die Organe, namentlich die Nieren, verbältnissmässig wenig verändert sind. Die meisten Fälle dieser Art betreffen Vergiftungen, welche durch einmalige Einverleibung einer sehr grossen Dosis (meist nüchtern) aus Irrthum hervorgerufen werden."

Eben deshalb, setzten wir gleich hinzu, verdienen diese Fälle unsere volle Beachtung, da ja in anderen Fällen, in welchen das chlorsaure Salz als Medieament gebrancht wurde, die Krankheitserscheinungen selbst das Vergiftungsbild getrïbt haben können. Ich muss noch einen $\mathrm{Zug}$ zu dem von v. Mering entworfenen Bilde hinzufügen, nämlich die Convulsionen und a usgesprochenen Krämpfe, welche nach seiner eigenen Zusammenstellung sowohl in dem von Chevallier schon im Jahre 1885 beobachteten Falle, wie in den von Riess und Tillner im Jahre 1882 mitgetheilten Fällen unverkennbar anwesend waren.

Wenn nun auch die bei Lebzeiten beobachteten Vergiftungserscheinuingen nöthigenfalls aus einer Blutzersetzung erklärt werden können und eine intensive Blutveränderung vielleicht auch hartnäckiges Erbrechen und profuse Diarrhoe hervorrufen kann, so werden diese beiden Erscheinungen dennoch viel leichter aus der Gastritis toxica erklärt, welche nothwendig der Einfuhr einer grösseren Menge eines reizenden Salzes folgen muss und welche dann auch in einem der Sectionsprotokolle ganz deutlich angetroffen wird.') Die hochgradige Dyspnoe, die tiefe Cyanose, die Herzsehwäche, die Convulsionen sind weiter theils als Reflexerscheinungen aus der Gastritis toxica, theils als durch Kaliwirkung verursacht $\mathrm{zu}$ betrachten, theils auch mit der acuten Wirkung einer in die Blutmasse aufgenommenen concentrirten Salzlösung in Zusammenhang zu bringen. Kein einziges Vergiftungssymptom zwingt mit Nothwendigkeit zu der Annahme einer so intensiven Blutveränderung, dass die Erhaltung des Lebens unmöglich wird, und die äusserst geringe Veränderung der

1) Brouardel et l'Hôte, Ann. d'Hygiène publique 1881. In dem zur Section gekommenen Falle zeigte die Magenschleimhaut eine ausgedehnte Blutekchymose, als ob sie mit einer Säure geätzt wäre. Siehe auch Blyth, Poisons. London 1884. S. 107. 
Nieren weist jedenfalls nur auf eine beginnende Reizung dieser Organe hin.

Wenn wir nun weiter v. Mering's Darstellung folgen, so finden wir in diesen minder rasch verlaufenden Fällen folgende Vergiftungserscheinungen:

I. Störungen in der Beschaffenheit der Haut (grauviolette Flecken der Hant und ikterische Verfärbung) und des Blutes (Auftreten von Methämoglobin im Blute und eigenthümliche Veränderungen der rothen Blatkörperchen), hochgradige Athemnoth und Herzschwäche.

II. Gastrointestinalstörungen, Schwellungen der Leber und Milz.

III. Functionsstörungen der Nieren: langwierige Oligurie und Anurie (Vorkommen im sparsam gelassenen Harn von Methämoglobin und Hämatin, Eiweiss, Detritusmassen von rothen Blutkörperchen in Form breiter brauner Cylinder oder gelbbrauner amorpher Schollen).

IV. Störungen des Nervensystems: urämische Erscheinungen.

Alle diese Erscheinungen, wozu noch die subjectiven Klagen der Kranken (Kopfweh, Appetitlosigkeit, Empfindlichkeit des Magens, besonders auf Druck, Schmerzhaftigkeit der Leber- und Lumbalgegend, intensive Brustbeklemmung und grosses Schwächegefïhl) kommen, müssen nun, nach der Blutzersetzungstheorie, aus der Anhäufung der Zerfallsproducte des Blutes in verschiedenen Organen, namentlich den Nieren, und die dadurch herbeigeführte Verstopfung der Harnkanälchen u. s. w. erklärt werden. Es werden also die Schwellung der Leber und Milz als eine Folge der Anhäufung des Methämoglobins im Blute, der Icterus als ein hämatogener dargestellt. Nur fragt es sich, wie man sich den Zusammenhang dieser Anhäufung der Zerfallsproducte des Blutes mit den Gastrointestinalstörungen denken muss, wie es kommt, dass in allen Fällen eben diese Gastrointestinalstörungen die ersten Symptome sind und bis zur Genesung oder den tödtlichen Ausgang fortdauern. Und eben auf diese Frage gibt die Blatzersetzungstheorie uns keine Antwort.

Schliesst man sich dagegen unserer Darstellung an, so können alle Erscheinungen ohne Mühe und in logischem Zusammenhange aus der localen Wirkung des Salzes auf die Magenschleimhaut und aus der entfernteren Wirkung der in das Blut aufgenommenen Kaliverbindung oder aus der Salzwirkung abgeleitet werden.

Es ist die durch die locale Wirkung des Salzes hervorgerufene toxische Gastritis, welche für die heftige Diarrhoe, das hartnäckige Erbrechen und für die subjectiven Beschwerden von Seiten des Magens verantwortlich gemacht werden muss, es is dies dieselbe locale Wirkung, welche beim Fortdauern des Lebens auch eine Schwellung der 
Duodenalschleimhaut veranlassen kann, als deren Folge ein echter Icterus catarrhalis, ein wahrer hepatogener Icterus auftritt. Dieser Icterus führt zur Gallenstauung und zur nothwendigen Volumvergrösserung der Leber, und ausserdem, wie jeder hepatogener Icterus, zur Schwellung der Milz. ${ }^{1}$ ) Die entferntere Kali- und Salzwirkung äussert sich als Herzschwäche und Athemnoth; die allmähliche Abscheidung des Salzes durch die Nieren, welche bei der eingebrachten grossen Menge mehrere Tage in Anspruch nimmt, führt ausserdem zu einer acuten toxischen Nephritis, wobei in geringer Menge ein Eiweiss, Blut und Harncylinder enthaltender Harn entleert wird, welcher um so mehr als ein für das Fortbestehen des Lebens gefährliches Moment betrachtet werden kann, weil ja ausserdem die Krankheit, welche za dem Missbrauch des Kaliumehlorats Veranlassung gab, vielleicht schon die Nieren getroffen hat. Es entwickeln sich dann die von der Urämie abhängigen Störungen des Nervensystems. Dass nun in dem von solchen Kranken stammenden blutigen Harn Methämoglobin gefunden werden muss, besonders wenn der so viel Chlorat enthaltende Harn vor der Untersuchung kürzere oder längere Zeit sich selbst iiberlassen war, ist nach unseren früheren Auseinandersetzungen (II, S. 192) ohne Weiteres klar. Man sieht, wie leicht alle Vergiftungserscheinungen sich erklären lassen und wie wenig Veranlassung da ist, noch irgend ein anderes unbewiesenes Moment zur Erklärung des Vergiftungsbildes heranzuziehen.

Nur eine Erscheinung bleibt scheinbar unerklärt. Es ist diejenige der grauvioletten Flecken der Haut, welche in dem von Marchand beobachteten Falle am 11. Tage der Krankheit, einen Tag also vor dem Tode, als ein rothfleckiges, masernähnliches Exanthem an den Vorderarmen und den unteren Extremitäten bemerkbar waren, in dem von Wegscheider mitgetheilten Falle auch nicht in den ersten Tagen der Vergiftung, sondern während des Verlanfs der 14 tägigen Krankheit als zahlreiche kupferrothe Flecken beobachtet wurden, welche auch in einem von $\mathrm{H}$ ofm e i er beobachteten, mit Scharlach complicirten Falle als dunkelkupferrothe Flecke anftraten und endlich als eigenthümliche blaue Flecke auf den Wangen auch in dem Brandscheider'schen Falle zur Beobachtung kamen. ${ }^{2)}$ In keinem der übrigen Fälle, welche zu v. Mering's Casuistik gehören, fand sich dieses Symptom. Ich bin nun wohl geneigt, dieses relativ seltene Symptom, welches ja nicht einmal von der Vergiftung direct abhängig zu sein braucht, auch als ein urämisches aufzufassen, da ja bei der Urämie derartige Flecken und Exantheme bekanntlich vorkommen können; in keinem Falle kann man aber behaupten, dass die Blutzersetzungstheorie mehr Aufklärung gibt über diese incon-

1) Mackay, Dieses Archiv. XIX. Bd. S. 269 .

2) v. Mering 1. c. S. 49.50. 
stante Erscheinung, welche, wenn sie durch die supponirte Blutzersetzung bedingt wäre, gewiss in den meisten Fällen nicht hätte fehlen können.

Wenn man sich die Mühe nimmt, in der älteren Literatur die Vergiftungsfälle zusammenzustellen, welche der seiner Zeit so hochgelobte Salpeter verursacht hat, so ergibt sich eine fast vollkommene Identität zwischen den durch diese beiden Kalisalze bewirkten Intoxicationen.

So lesen wir z. B. bei Orfila ${ }^{1}$ ) folgenden von Laffize im Jahre 1787 beobachteten Fall: Eine Dame nahm des Morgens anstatt schwefelsaure Magnesia eine Unze $(24 \mathrm{~g})$ salpetersaures Kali in einem Glas Vasser mit 2 Unzen Aepfelsyrup. 1/4 Stunde später stellten sich folgende Symptome ein: Cardialgie, Ekel, schmerzhaftes Erbrechen, Diarrhöen, dann Convulsionen, welche den Mund verzerrten, zuletzt fast unfühlbarer, schwacher Puls, kalte Extremitäten, schreckliche, durch nichts zu stillende Schmerzen im Unterleibe, D y spnoe. Tod nach 3 Stunden. So wurde weiter in einem ron Deutseh mitgetheilten Falle, welcher in Genesung überging, während längerer Zeit eine gestörte Harnsecretion beobachtet. ${ }^{2}$ )

Zwar könnte man nun nach der Binz-Barth'schen Darstellung ${ }^{3}$ ) anch für die toxische Wirkung des Salpeters eine Blutzersetzung verantwortlich machen wollen, denn auch bei der toxischen Wirkung des Natriumnitrats soll das Nitrat zum Theil in Nitrit übergehen und eine Reduction im lebenden Organismus und im lebenden Blut erfahren, aber dagegen muss bemerkt werden, dass nach Anwendung des Chilisalpeters beim Menschen und Thier im vollständig reinen Harn von $\mathrm{Kobert}$ kein Nitrit aufgefunden werden konnte ${ }^{*}$ ) und dass die von Barth bei Fröschen und Kaninchen dureh Natriumnitrat hervorgerufenen toxischen Erscheinungen im Grunde keine anderen $z \mathfrak{u}$ sein scheinen, als diejenigen, welche unter dem Einflusse einer concentrirten Salzlösung beobachtet werden können. $\left.{ }^{5}\right)$ Wenn man aber trotzdem in der Identität der durch Kali chloricum und Kali nitricum verursachten Vergiftungsbilder keinen triftigen Grund anerkennen wollte, um beide auf Kaliwirkung und concentrirte Salzwirkung zurückzuführen, so liefern, abgesehen von den frïher schon mitgetheilten experimentellen Thatsachen, die in

1) Traité des poisons. 1818. II. éd. p. 119.

2) Med. Times and Gazette. 1856. 30. Aug.

3) Barth, Toxikol. Untersuchungen über Chilisalpeter. Bonn 1879.

4) Falck, Toxikologie. 1880. S. 116 Anmerkung.

5) Das durch Barth beschriebene Vergiftungsbild, sowie die von Natriumnitrat zur Herbeiführung einer sogenannten Narkose bei Fröschen nöthige Dosis stimmen absolut mit den von uns bei Anwendung einer concentrirten Kochsalzlösung in dieser Beziehung constatirten Thatsachen. 
der Literatur verzeichneten Fälle von Vergiftung durch Kaliumsulfat in dieser Beziehung den endgïltigen Beweis für die Richtigkeit unserer Anschauungen. Es hat bis jetzt noch kein Forscher daran gedacht oder daran denken können, eine durch dieses Salz hervorgerufene Blutzersetzung oder eine Reduction dieses Salzes im lebenden Organismus $\mathrm{zu}$ vermuthen. Und dennoch ist das Vergiftungsbild des $\mathrm{Ka}$ liumsulfats - wie man sich davon aus den von Orfila ${ }^{1}$, Christi son ${ }^{2}$ ), Tay! $0 r^{3}$ ) mitgetheilten Fällen überzeugen kann - kein anderes wie diejenigen des Kaliumchlorats und Kaliumnitrats. Heftiges Erbrechen, profuse Diarrhoe, Magen - und Bauchschmerz, Herzschwäche, Athemnoth, Convulsionen stellen auch hier das Vergiftungsbild dar. ${ }^{4}$ )

Und was schliesslich den einzigen in der Literatur verzeichneten Fall von Vergiftung und Tod durch chlorsaures Natron anlangt, so stimmen die bei demselben von $\mathrm{Jacobi}^{5}$ ) beobachteten Erscheinungen und die von diesem Autor angeschuldigte Todesursache: acute diffuse Nephritis, so gut zu unserer Darstellung, dass wir darüber kein Wort weiter zu verlieren brauchen.

Nun könnte vielleicht die relativ kleine Dosis, 10 Drachmen $=40 \mathrm{~g}$, Wunder nehmen. Die letale Dosis des Kochsalzes - welches sich nach

1) Traité des poisons. 1818. I. p. 560 .

2) A Treatise on Poisons. Edinburgh. 1841. p. 657.

3) On poisons. London 1859 . p. 340.

4) Die giftigen Eigenschaften des Sal polychrestum, Sal de duobus, welches im vorigen Jahrhundert als ein Specificum gegen das Milchfieber der Wöchnerinnen sehr vielfach und in grossen Dosen verordnet wurde, waren schon damals Soba ux bekannt. Er beobachtete schon die der Vergiftung zukommenden Baucbschmerzen, die Convulsionen in den oberen und unteren Extremitäten, die Anurie und fand darin Ursache ,pour le faire repentir de l'avoir mis en usage ${ }^{26}$. Der erste letal endigende Fall ward von Bayard und Chevallier im Jahre 1842 (Annales d'Hygiène publique. 1842. T. XXVII. p. 397-437) mitgetheilt. Die Vergiftung betraf eine 25 jährige gesunde Wöchnerin, welche nach der Vorschrift ihres Arztes in $1 \frac{1 / 2}{2}$ Stunden $40 \mathrm{~g}$ Kaliumsulfat gebrauchte und, nachdem sich Erbrechen und Diarrhoe eingestellt hatte, unter den Erscheinungen einer „chaleur ardente dans la bouche, l'estomac et le ventre, avec de l'engourdissement et des crampes aux membres supérieurs et inférieurs, puis des étouffements" innerhalb $33^{1 / 4}$ Stunden nach der Einnahme der ersten Dosis verschied. Die hinzugezogenen Aerzte vermutheten eine Verunreinigung des Salzes und erklärten, dass der Tod nicht durch das Kaliumsulfat herbeigeführt sein könnte, bei der gerichtlichen Untersuchung ergab sich aber das Salz als vollkommen chemisch rein und das Obergutachten nahm dann auch den Tod als durch Kaliumsulfat verursacht an, unter dem begünstigenden Einflusse der bei der Wöchnerin obwaltenden speciellen Zustände (conditions spéciales).

5) v. Mering 1. c. S. 43 . 
unserer Darstellung in seinẹ Wirkung auf den thierisehen Organismus als ganz vollkommen identisch mit dem chlorsauren Natron herausstellt war doch in den von Christis on ${ }^{1)}$ nnd Taylor ${ }^{2}$ ) mitgetheilten Fällen eine viel grössere, sie betrug $1 / 2-1$ Medicinpfund $(180-360 \mathrm{~g})$. Aber man muss bedenken, dass der von J a cobi mitgetheilte Fall einen Kranken, keinen Gesunden betraf, und dass nach Christison bei Gesunden schon 15-60 g trocken genommenes Kochsalz toxische Erscheinungen zu erzielen vermögen.

Ich kann hiermit meine Aufgabe als erledigt betrachten. Es ist mir hoffentlich der Beweis gelungen, dass von einer besonderen eigenthümlichen toxischen Wirkung der chlorsauren Alkalisalze keine Rede sein kann und dass die Giftwirkung dieser Substanzen theils der irritirenden (resp. corrodirenden) Wirkung jeder stark concentrirten Salzlösung, theils den physiologisehen Wirkungen ibrer alkalischen Componenten zugeschrieben werden muss.

Die für die Praxis aus dieser Auffassung sich ergebenden Schlussfolgerungen sind einfach und stimmen mit den von v. $\mathrm{Me}$ ring gegebenen Rathschlägen ${ }^{3}$ ) fast ganz überein. Man gebe die chlorsauren Alkalisalze nicht in zu grosser Menge auf einmal, nicht in zu concentrirter Lösung und nicht unter Umständen, welche der Aufnahme des Salzes in das Blut oder der irritirenden Wirkung förderlich sein können, nie also in grösseren Gaben bei leerem Magen. Bei fast allen sicher constatirten Vergiftungen durch chlorsaures Kali wurde eine sehr concentrirte Lösung oder das Salz in Substanz im nüchternen Zustande in grösserer Menge - meist aus Versehen genommen. Dagegen hat sich der wiederholte Gebranch kleiner Gaben in diluirter Lösung (1/2-2 Proc.) als vollkommen gefahrlos ergeben und ist kein einziger sicher constatirter Fall bekannt, in welchem beim Erwachsenen eine mittlere Tagesgabe von $3-5-8 \mathrm{~g}$ Kali chloricum (in nicht zu concentrirter Lösung) irgend welche nachtheiligen Folgen verursacht hat. Dass man mit der Anwendung von Kalisalzen und also auch mit derjenigen des chlorsauren Kali vorsichtig sein muss, wenn die Harnsecretion entweder primär oder secundär darniederliegt, braucht nicht besonders hervorgehoben zu werden. Unter diesen Umständen kann es doch vielleicht zu einer Anhäufung der Kalisalze in dem Blute kommen, da die Ausscheidung der Kalisalze in der Regel nur langsam vor sich geht. Dann würde also das chlorsaure Natron den Vorzug verdienen, ebenso wie in allen

1) 1. c. S. 657 und 658 .

2) l. c. S. 3.

3) 1. c. S. $136-139$. 
den Fällen, in welchen man zu irgend einem therapeutischen Zwecke grössere Mengen der chlorsauren Alkalisalze anwenden will. Nur muss selbstverständlich auch bei dem chlorsauren Natron die irritirende und giftige Wirkung concentrirter Lösungen nie aus dem Auge gelassen werden und die angewandte Lösung darf eine gewisse mittlere Concentration (3-5 Proc. z. B.) nicht übersteigen. Wenn man übrigens meint, dass der Gebrauch der chlorsauren Alkalisalze auch bei Fiebererscheinungen oder Störungen der Respiration besondere Vorsicht erheischt, und man andererseits in der Transfusion ein Mittel zur Bekämpfung der Vergiftungserscheinungen erblickt ${ }^{1}$ ), so hat man sich zu diesem Ausspruch nur durch unrichtige theoretische Deductionen verführen lassen, da für einen nachtheiligen Einfluss dieser Bedingungen kein einziger Grund angeführt werden kann. Muss man nun dafür eintreten, dass das chlorsaure Kali dem Handverkauf in den Apotheken und Droguenhandlungen entzogen werde? Das chlorsaure Kali ist ganz gewiss nicht giftiger wie alle anderen Kaliumsalze, das chlorsaure Natron nicht giftiger wie Kochsalz. Man müsste also dieselben Maassregeln für alle in der Medicin gebräuchlichen Alkalisalze nehmen, bei deren Gebrauch in grossen Gaben auf einmal schon Vergiftung und Tod beobachtet ist, und wenn man logisch verfahren wollte, auch das Kochsalz unter diese Substanzen rechnen. Davon kann nun wohl keine Rede sein, denn wohin würde es führen, wenn man alle Arznei-, Nahrungs- und Genussmittel, welche auf einmal in zu grossen Gaben gereicht oder genommen dem Organismus schaden können, dem Handverkauf entziehen wollte? Dagegen lässt sich nun freilich einwenden, dass die Frequenz der Vergiftungsfälle durch Kali chloricum in den letzten Jahren gegenüber der Frequenz der Vergiftungsfälle durch andere neutrale Alkalisalze eine ungeheuer grosse genannt werden muss. Unter diesen Fällen gibt es vielleicht einige, in welchen man zu voreilig aus der an der Leiche gefundenen Blutveränderung auf eine Chloratvergiftung als Todesursache geschlossen hat, aber wenn man auch diese ausscheidet, so können doch leicht aus der Literatur der letzten 10 Jahre 20-30 Fälle gesammelt werden, in welchen grosse Gaben Kali chloricum auf einmal aus Versehen oder aus Unachtsamkeit zweifelsohne den Tod verursacht haben. $O b$ daraus für den Staat die Pflicht erwächst, gegen diesen Missbrauch einzuschreiten, ist eine Frage, deren Beantwortung nicht hierher gehört. Nur darauf möchte ich hinweisen, dass auch hier Aufklärung des Laien und des

1) v. Mering 1. c. S. 137 und 138. 
medicinischen Publikums ïber die Wirkungsweise dieser Salze am meisten dazu beitragen wird, die Frequenz der Vergiftungsfälle herabzusetzen, wie dies auch mit den Vergiftungen durch Kali nitricum und Kali sulfuricum der Fall gewesen ist, deren Frequenz im vorigen und im Anfange dieses Jahrhunderts jetzt nur noch eine historische und wissenschaftliche Bedeutung hat.

Schliesslich kann ich nicht unerwähnt lassen, dass der erste Autor, welcher auf die Giftigkeit grosser Gaben chlorsauren Kalis aufmerksam gemacht hat, J a co bi, in seiner Darstellung der toxischen Wirkung dieser Substanzen bauptsächlich auf die dadurch erzengten gastrischen Störungen, die Beeinträchtigung der Herzthätigkeit und die herbeigeführte Nierenentzündung hingewiesen hat und also schon im Jahre 1860 denselben Standpunkt einnahm ${ }^{1}$ ), welchen ich in dieser Arbeit als den richtigen zu bezeichnen bestrebt war. Dass nun auch mit Bezug auf die therapentische Wirkung der Chlorate derselbe Standpunkt behauptet und auch diese Wirkung auf eine einfache Salzwirkung zuruickgefïhrt werden muss, möchte a priori manches Bedenken erregen. Sind nicht auf kranken Schleimhäuten bei Diphtberitis, bei Stomatitis mercurialis u. s. w. Fäulniss- und Gährungserreger in genizgender Menge vorhanden, um eine Reduction des angewandten Salzes zu erzeugen, und ist der Heileffect nicht den sehr kleinen, dabei allmählich frei werdenden Mengen Sauerstoff zu verdanken? Ich möchte zwar nicht die Möglichkeit dieser Zersetzung von vorneherein in Abrede stellen, aber wenn ich den XIX. Versuch v. Mering's ${ }^{2}$ ) genauer ins Auge fasse, aus welchem sich ergibt, dass selbst bei einer an Stomatitis mercurialis leidenden Kranken, welche eine Kali chloricum-Lösung als Gurgelwasser gebrauchte und nach längerem Gurgeln verschluckte, fast alles chlorsaure Kali im Harn wieder gefunden werden konnte, dann scheint es mir, als ob auch für den therapeutischen Effect dieser Verbindungen die durch dieselben hervorgerufene Salzwirkung mehr Bedeutung hat, wie die bis jetzt unbewiesene Abgabe von Sauerstoff.

1) American med. Times. 1860. v. Mering 1. c. S. 43.

2) 1. c. S. 69 . 